OPEN ACCESS

Edited by:

Julia C. Basso,

Virginia Tech, United States

Reviewed by:

Rosalina Fonseca,

New University of Lisbon, Portugal Rita Sleimen-Malkoun,

Aix-Marseille Université, France

*Correspondence:

Parvin Babae

p_babaei@gums.ac.ir

Specialty section:

This article was submitted to

Cognitive Neuroscience,

a section of the journal

Frontiers in Human Neuroscience

Received: 06 September 2021

Accepted: 16 December 2021

Published: 27 January 2022

Citation:

Babaei P and Azari HB (2022)

Exercise Training Improves Memory

Performance in Older Adults:

A Narrative Review of Evidence

and Possible Mechanisms.

Front. Hum. Neurosci. 15:771553.

doi: 10.3389/fnhum.2021.771553

\section{Exercise Training Improves Memory Performance in Older Adults: A Narrative Review of Evidence and Possible Mechanisms}

\author{
Parvin Babaei ${ }^{1,2,3 *}$ and Helya Bolouki Azari ${ }^{1,4}$ \\ ${ }^{1}$ Neuroscience Research Center, School of Medicine, Guilan University of Medical Sciences, Rasht, Iran, ${ }^{2}$ Cellular \\ and Molecular Research Center, School of Medicine, Guilan University of Medical Sciences, Rasht, Iran, ${ }^{3}$ Department \\ of Physiology, School of Medicine, Guilan University of Medical Sciences, Rasht, Iran, ${ }^{4}$ Department of Physiology, Tehran \\ University of Medical Sciences, Tehran, Iran
}

As human life expectancy increases, cognitive decline and memory impairment threaten independence and quality of life. Therefore, finding prevention and treatment strategies for memory impairment is an important health concern. Moreover, a better understanding of the mechanisms involved underlying memory preservation will enable the development of appropriate pharmaceuticals drugs for those who are activity limited. Exercise training as a non-pharmacological tool, has been known to increase the mean lifespan by maintaining general body health and improving the cardiovascular and nervous systems function. Among different exercise training protocols, aerobic exercise has been reported to prevent the progression of memory decline, provided adequate exertion level, duration, and frequency. Mechanisms underlying exercise training effects on memory performance have not been understood yet. Convergent evidence suggest several direct and indirect mechanisms at molecular and supramolecular levels. The supramolecular level includes improvement in blood circulation, synaptic plasticity and neurogenesis which are under controls of complex molecular signaling of neurotransmitters, neurotrophic factors, exerkines, and epigenetics factors. Among these various factors, irisin/BDNF signaling seems to be one of the important mediators of crosstalk between contracted skeletal muscles and the brain during exercise training. This review provides an affordable and effective method to improve cognitive function in old ages, particularly those who are most vulnerable to neurodegenerative disorders.

Keywords: exercise training, neurogenesis, neurotrophic factors, myokines, memory, adipokines

\section{HIGHLIGHTS}

- Exercise training enhances memory performance via neuroplastic alterations.

- Long-lasting moderate aerobic exercise is a more efficient neuroprotective modality.

- Exercise-induced memory improvement might be mediated via neurotrophic factors, and exerkines.

- Irisin/BDNF signaling is an important link between skeletal muscles and the brain. 


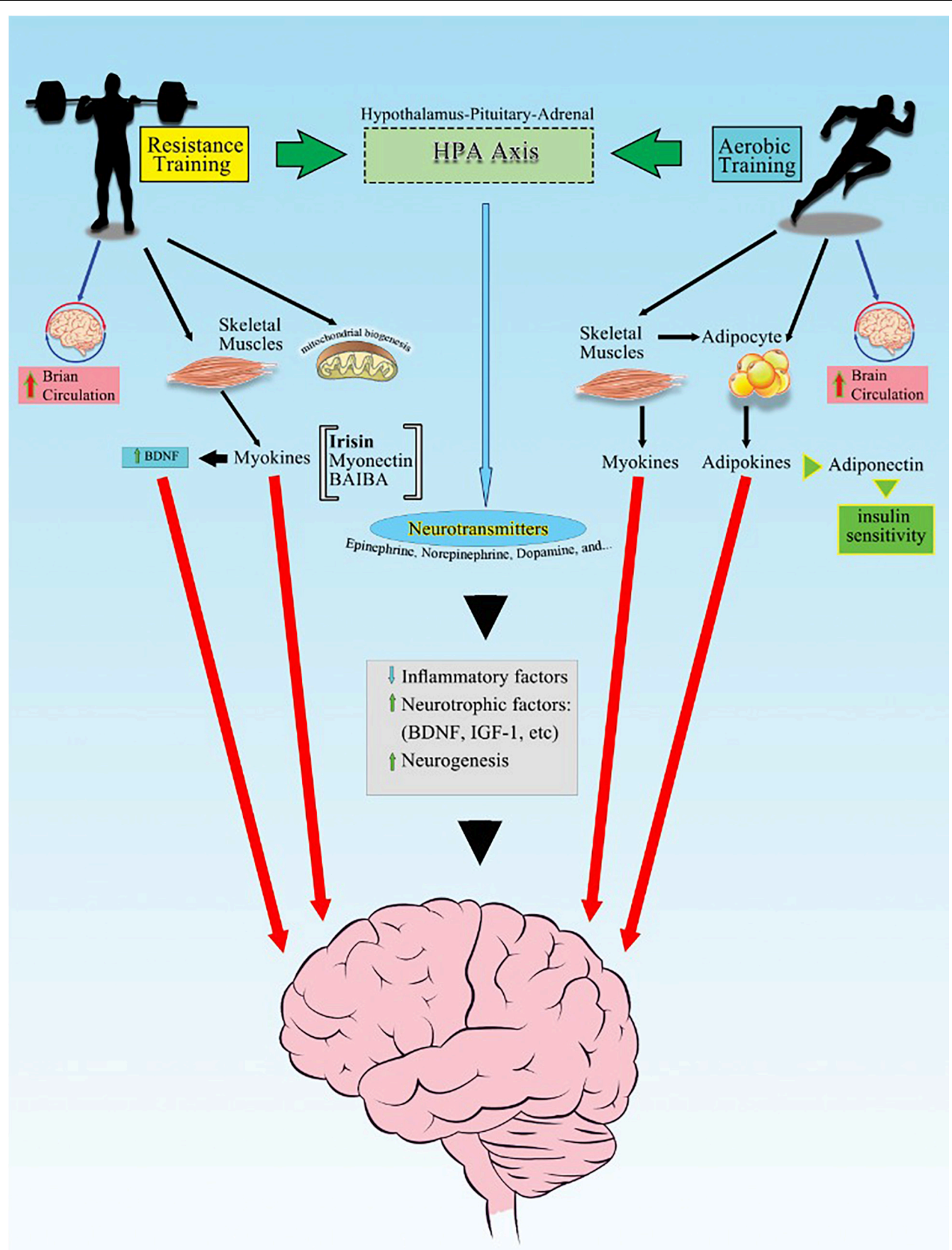

†emory improvment $†$

GRAPHICAL ABSTRACT | Exercise, neurotransmitters, growth factors, myokines, and potential effects on the brain.

\section{INTRODUCTION}

\section{Epidemiological Overview}

Cognitive function has been known to be negatively associated with aging (Plassman et al., 2007), genetic predisposition, cardiovascular disease, and type 2 diabetes (Grøntved and $\mathrm{Hu}$, 2011). Currently, 35.6 million people worldwide live with dementia which is predicted to double to 75.6 million by 2030 , thus, soon cognitive deficit will be a major public health priority (World Health Organization, 2020). The 
reasons responsible for the cognitive deficit are not yet well established. However, some assumptions have arisen, and among them, the reduction in the speed of information processing, sensorial deficit, decline in learning, and memory capability due to aging are more prominent (Ball and Birge, 2002; Kramer and Willis, 2002).

On the other hand, exercise training as a healthy lifestyle factor reduces the likelihood of developing dementia or slow down the progress of cognitive decline both in normal aging and dementia (Larson et al., 2006; Rolland et al., 2007; Chang et al., 2010, 2012; Buchman et al., 2012; World Health Organization, 2019; Lewis et al., 2020). It has been reported that engagement in exercise training by $5 \%$ over 5 years, reduces the percentage of patients with dementia by $11 \%$ (Grøntved and $\mathrm{Hu}, 2011$ ).

Considering the remarkable evidence indicating positive association between exercise training and cognitive function, the American College of Sports Medicine (ACSM) and the American Heart Association (AHA) recommended daily exercise for adult individuals (Voss et al., 2010).

\section{COGNITIVE FUNCTION}

Cognitive function refers to higher-level functions of the brain and includes different modalities such as acquiring knowledge, perception, attention, judgment, decision making, processing speed, executive function, cognitive flexibility, task switching, comprehension, response inhibition, and memory performance (Lezak et al., 2004; Diamond, 2013). Cognitive flexibility is an ability associated with adjusting mental activity and content, switching between different task rules and corresponding behavioral responses, maintaining multiple concepts simultaneously, and shifting internal attention between them to make a better adaptation to a new context (Scott, 1962; Cooper-Kahn and Laurie, 2008). Also, the ability to simultaneously consider two aspects of an object, idea, or situation at one point in time refers to cognitive flexibility, which requires aspects of inhibition, attention, working memory, response selection, and goal maintenance (Miyake et al., 2000; Sheet, 2005). Cognitive flexibility is mediated via a complex network including the front parietal cortex, cingulate cortex, mesolimbic, and striatum (ventral and dorsal parts) (Nowrangi et al., 2014; Hall and Fong, 2015). Considering the complexity of cognitive flexibility elements, the related neural networks, and limitation in the existing literature, we decided to review the effects of exercise training only on memory; as a vital component of cognitive flexibility.

The memory is an exciting capability of brain which preserves and stores acquired information and enables performing of adequate behavior based on lifelong experience (Magila and Xavier, 2012). Any deficits in memory retrieval might have deleterious implications on individual routines and health (Colcombe and Kramer, 2003).

Therefore, the arguments developed in this review focused on exercise training's effects on memory performance and is not intended to cover all aspects of cognitive function.

\section{Exercise Effects on Memory Performance}

Exercise training is defined as planned, structured, and repetitive exercise (Caspersen et al., 1985). There are remarkable pieces of evidence indicating that regular exercise training slows down the progress of cognitive decline (Erickson et al., 2011; World Health Organization, 2019; Lewis et al., 2020), and maintain the brain's cognitive ability, particularly memory, however, there are inconsistencies in the literature due to the variety in type and timing of the cognitive tests, subjects characteristics (Sibley et al., 2006; Lambourne and Tomporowski, 2010; Chang et al., 2012), and exercise protocols (Loprinzi et al., 2019a).

Some researchers believe that working memory is improved by chronic exercise, but not acute, in elderly individuals (Smith et al., 2010; Rathore and Lom, 2017; Damirchi et al., 2018), elite soccer players (Babaei et al., 2014); and in Alzheimer's disease patients (Vreugdenhil et al., 2012). Both animal study in aged rats with the Parkinson's disease (Tsai S.-F. et al., 2018; Tsai et al., 2019), and human study in patients diagnosed with Alzheimer's disease (Jia et al., 2019) and also in healthy adults (Babaei et al., 2014), recommended engaging in exercise training for 16-24 weeks, at least up to 3 times per week with $30 \mathrm{~min}$ per session, in order to achieve better outcomes on working memory. Liu et al. (2020), in patients with dementia confirmed that both strength aerobic and resistance training programs over 4 weeks can bring about significant cognitive benefits. In contrast with chronic protocols, Loprinzi et al. (2019a) reported that acute moderate-intensity exercise prior to memory encoding is capable to enhance short and long-term memories in healthy individuals (Loprinzi et al., 2019a). The relationship between acute exercise and memory is complex to conclude, and may vary based on the temporality, intensity of exercise, and the memory type evaluated.

Taken altogether, regular chronic type of training is more prominent for memory facilitation.

In the next section we discuss about the effect of intensity of training on memory performance.

\section{The Effect of Exercise Intensity on Memory Performance}

Besides the modalities of exercise training discussed above, the intensity of exercise training in relation to memory tests is important as well. Some studies suggest a dose-effect relationship between aerobic activity and executive function (Masley et al., 2009; Pyke et al., 2020), but, some believe in a reverse u shape pattern, meaning that a moderate-intensity exercise would improve memory, whereas high-intensity exercise would impair memory performance (Brisswalter et al., 2002; Kashihara et al., 2009; Ruscheweyh et al., 2011; Frith et al., 2017).

It should be noticed that, the timing of memory tests is very important too. Loprinzi et al. (2019b) reported that acute moderate-intensity exercise prior to memory encoding enhances short and long-term memories in healthy participants (Loprinzi et al., 2019a), however high-intensity acute exercise impairs working and episodic memories (Loprinzi et al., 2019b).

In addition, a decline in cognitive performance of adults, when measured during acute high-intensity physical exercise 
(Isaacs, 1991; McMorris and Keen, 1994), or immediately after the exercise (Covassin et al., 2007; Bue-Estes et al., 2008; Moore et al., 2012) have been found. Moreover, the declines in working memory, verbal memory, and attention have been shown to be transient following intense activity in adults (Covassin et al., 2007; Bue-Estes et al., 2008; Moore et al., 2012), and children (Samuel et al., 2017).

A recent study reported that a single bout of maximal intensity exercise in children can transiently impair complex tasks such as verbal learning, which resolves after a 1-h rest. On the other hand, more simple cognitive tasks that apply short-term working memory are not negatively affected by such an activity, and may even be facilitated after adequate rest (Samuel et al., 2017). Therefore, adequate recovery from intense exercise might result in enhanced working memory abilities (Bue-Estes et al., 2008), indicating both debilitating (Covassin et al., 2007; Bue-Estes et al., 2008; Moore et al., 2012) and facilitating (Bue-Estes et al., 2008) effects of physical activity.

Overall, when high-intensity acute exercise occurs before or during the memory task, it may be less favorable for working memory, and may not associate with long-term memory function, as opposed to when it occurs shortly after memory encoding (Hötting et al., 2016; Loprinzi, 2018).

Also, exercising shortly after memory encoding is slightly less advantageous for both moderate (Labban and Etnier, 2011; Sng et al., 2018) and high-intensity exercise (Frith et al., 2017) compared to pre encoding.

Interestingly, in contrast with the negative relationship between high-intensity exercise and memory performance which discussed above, Wilke (2020) believes that high-intensity functional training represents an appropriate method to acutely improve working memory, in healthy middle-aged individuals. One of the explanations for discrepancy in findings possibly related to the fatigue which plays a more important role on the cognitive responses to an exercise bout.

Collectively, there is an intensity-specific effect of exercise on memory, and results may differ based on the memory tests, the temporality of memory assessment, the time elapsed from completion of the exercise, and the method of estimating the intensity of exercise training.

Additional works exploring the effects of a variety of exercise types (e.g., continuous, intermittent, strength, aerobic, combined-type) under different intensities and durations upon memory storage and retrieval are needed.

\section{Possible Mechanisms of \\ Exercise-Induced Memory Improvement}

Although mechanisms underlying exercise training effects on memory improvement have not been understood well, there are both direct and indirect mechanisms at molecular and supramolecular levels. The supramolecular level refers to the alteration in the physiological functions or structural changes in organs such as increase in blood circulation or hippocampal volume (Colcombe and Kramer, 2003; Smith et al., 2010; McAuley et al., 2011; Guiney and Machado, 2013). The supramolecular alterations, per se are under the control of complex molecular signaling pathways. For instance, increasing gray matter integrity, and hippocampal volume (Colcombe and Kramer, 2003; Smith et al., 2010; McAuley et al., 2011; Guiney and Machado, 2013) are mostly related to neurogenesis (Sibley et al., 2006; Chang et al., 2012; Foster, 2015) and elevation in neurotrophic factors (Hötting et al., 2016).

Below, we discuss in more detail some of the selected molecular mechanisms underlying exercise's beneficial effects on learning and memory.

\section{Brain Circulation}

Regular physical activity has been reported to improve brain circulation (Erickson et al., 2012) particularly the hippocampus; an area important for learning and memory (Pereira et al., 2007; Burdette et al., 2010; Mandolesi et al., 2017). How exercise leads in elevated circulation and further memory improvement, has not been clarified yet. It is assumed that skeletal muscles induces the secretion of lactate, during contraction, then, lactate is taken up by the brain regions (Ide and Secher, 2000), and causes excitability of the primary motor cortex (Coco et al., 2010), increases brain vascular endothelial growth factor (Morland et al., 2017) and density of cerebellar cortex vessels (Castellano et al., 2017). Besides providing adequate pumping and oxygenation of the blood, lactate increases brain metabolism by ketone uptake and utilization.

Adequate circulation also provides clearance of the brain waste products such as amyloid-beta; an important abnormal protein in the frontal cortex and hippocampus of $\mathrm{AD}$ patients (Jørgensen et al., 1992; Adlard et al., 2005; Jessen et al., 2015; von Holstein-Rathlou et al., 2018; Li et al., 2019). Collectively, all these mechanisms prevent neural damages, and potentially improve the acquisition and retrieval of memory.

\section{Neurogenesis}

The higher cardiorespiratory fitness and physical activity in aged subjects, have been found to be associated with greater brain structures integrity, and better memory performance (Burzynska et al., 2015). Previous studies confirmed that, exercise training increases gray matter integrity in brain, and volume of brain regions, particularly entorhinal cortex and hippocampus in both human and animal studies (Voss et al., 2013; Ten Brinke et al., 2015; Chieffi et al., 2017; Firth et al., 2018; Tsai S.-F. et al., 2018; Clark et al., 2021), and also, brain white matter of memoryrelated regions in people with mild cognitive impairment (Amjad et al., 2019). In addition, reduced hippocampal atrophy together with improved memory were reported following 6-12 weeks of exercise training in early stage of Alzheimer's disease with this finding (Chirles et al., 2017; Ma et al., 2017; Morris et al., 2017). Interestingly, it seems beneficial effects of exercise on brain structures mostly are found in the regions sensitive to neurodegeneration such as the hippocampus and the neocortex in healthy elderly and also adults with Alzheimer's disease or mild cognitive impairment (Haeger et al., 2019).

How exercise leads in neurogenesis and memory improvement has not been clarified yet. Some researchers believe that intensive exercise training, produces lactate (Scandella and Knobloch, 2019; Nicola and Okun, 2021), and 
then, lactate stimulates neurons and glia cells proliferation (Steiner et al., 2004; Hirase and Shinohara, 2014; El Hayek et al., 2019), particularly in the hippocampus (Ohia-Nwoko et al., 2014; Elahi et al., 2016). Moreover, lactate induces brain derived neurotropic factor (BDNF) expression in the hippocampus, and then BDNF stimulates neurogenesis (El Hayek et al., 2019).

\section{Mitochondrial Biogenesis}

An important aspect of exercise training, is the contraction of skeletal muscles, which is associated with enhanced mitochondrial function. There is a bidirectional relationship between the brain and skeletal muscles in a way that both organs benefit from exercise, in order to get adaptation, and in this scenario, mitochondria play pivotal roles in cells survival, metabolism, and oxidative stress (Hood et al., 2019; Burtscher et al., 2021). Studies showed that the number of mitochondria are decreased with aging in healthy adults (Flockhart et al., 2021), and are increased by exercise training (Damirchi et al., 2012; Hood et al., 2019; Huertas et al., 2019; Granata et al., 2021). Exercise training increases antioxidant capacities and the affinity of mitochondria for oxygen (Sun et al., 2016; Hood et al., 2019), also increases proteins involved in energy production and ATP (Bishop et al., 2019; Hood et al., 2019), and finally stimulates mitophagy in skeletal muscles (Bishop et al., 2019; Burtscher et al., 2021), and brain (Navarro et al., 2004; Steiner et al., 2011; Li et al., 2019). Mitochondrial biogenesis after exercise training, is mediated by $5^{\prime}$ adenosine monophosphate-activated protein kinase (AMPK) and peroxisome-proliferator-activated receptor $\gamma$ coactivator- $1 \alpha$ (Short et al., 2005).

On the other hand, mitochondria produce reactive oxygen species (ROS) (Clark and Simon, 2009), in response to intensive acute exercise (Holloway, 2017), which implicates the pathogenesis of several brain disorders (Pesta and Roden, 2017; Zorova et al., 2018). It should be noticed that, exerciseinduced ROS levels, can affect redox regulation in brain (Aguiar et al., 2008), and endogenous antioxidant capacities (Quan et al., 2020). In other words, mitochondria are double-edged swords with both beneficial and detrimental effects on memory performance. They not only produce antioxidants molecules, but also increase $\mathrm{Ca}^{++}$and ROS in cytoplasm. Recently, we showed that blocking mitochondrial calcium uniporter, inhibits $\mathrm{Ca}^{++}$neurotoxicity and alleviates cognitive decline in AD model of rats (Nikseresht et al., 2021). There is not clear yet, how it could be possible to keep a balance between antioxidants and ROS in mitochondria (mithohormesis) by exercise training. According to the theory of "Hormesis," response to exercise might be biphasic, depending on the baseline physical fitness status of individuals (Seifi-Skishahr et al., 2016), and the amounts of ROS (Quan et al., 2020). In other word, exercise might be protective at moderate levels, but, detrimental at high levels in healthy adults (Flockhart et al., 2021). Therefore, regular exercise may prevent the aging-related decline of mitochondrial function.

Taken all together, a lifestyle with moderate regular exercise training, appears to be more useful to improve health by making the balance between oxide and redox state in cells.

\section{Neurotrophic Factors}

As we mentioned earlier, the relationship between contracted muscles and the brain has been questionable for years. It has been assumed that the number of dendritic connections and neural plasticity is related to the neuroendocrine and humoral alterations promoted by exercise (Isaacs et al., 1992; Santos, 1994). Currently, it has been proposed that, when skeletal muscles are contracted, they start to secrete various proteins, known as myokines into the circulation (Pedersen and Febbraio, 2012). Then, these molecules might elevate neurotrophic factors such as irisin, brain-derived neurotrophic factor (BDNF), and insulinlike growth factor (IGF-1) (Delezie and Handschin, 2018), which all are involved in hippocampal plasticity and long term memory (Lynch et al., 2008; Tanaka et al., 2008; Duzel et al., 2016) following exercise in both animals (Gobbo and O'Mara, 2005; Babaei et al., 2017) and human subjects (Belviranli et al., 2016; Damirchi et al., 2018).

In the next section, we discuss the mechanisms by which, BDNF and irisin might impact on memory and learning.

\section{Brain Derived Neurotropic Factor}

Exercise training has been known to increase serum BDNF levels, parallel with memory improvement in healthy individuals (Babaei et al., 2013, 2014; Damirchi et al., 2014; Szuhany et al., 2015; Belviranli et al., 2016; Marinus et al., 2019) and roddents (Erickson et al., 2010; Babaei et al., 2017; El Hayek et al., 2019). These findings support the pivotal role for exercise-induced BDNF in brain (Numakawa et al., 2018; Di Liegro et al., 2019). However, there are differences in the baseline level of BDNF considering the subjects' characteristics. For example, Babaei et al. (2014) showed that long-term habitual exercise in elite athletes is associated with a lower resting level of serum BDNF and better memory. In contrast to elite athletes, a higher level of serum BDNF was detected in subjects diagnosed with metabolic syndrome (MetS) (Damirchi et al., 2014), which might reflect the compensatory role for BDNF.

Collectively, recent studies confirm that, exercise training increases circulatory BDNF levels, regardless of their type, intensity, duration, and subject's health status (Feter et al., 2019; Marinus et al., 2019). Babaei et al. (2014) showed an increase in serum BDNF level after an acute aerobic/anaerobic exercise in both elite athletes and sedentary subjects. Although Feter et al., 2019 reported that interventions lasting at least 12 weeks with a session duration of $40 \mathrm{~min}$ would be the most prominent strategy for increasing BDNF levels in healthy or unhealthy adults (Feter et al., 2019). In contrast, overtraining seems to reduce BDNF level, but upregulates its receptors of " $p 75$ " and tropomyosin receptor kinase B (TRKB), in intact mice (Xu et al., 2020). Therefore, BDNF releasing system keeps enough sensitivity to be elevated, whenever encountering the different forms of exercise training, although acute exercising is more prominent.

The cellular and molecular mechanisms of exercise-induced BDNF have not been understood yet. El Hayek et al. (2019) suggested that lactate released during exercise by skeletal muscles, crosses the BBB and induces BDNF expression, and activates TRKB signaling in the hippocampus. The function of lactate is dependent on the activation of the transcriptional coactivator; 
PGC-1 $\alpha$, and the secreted molecule fibronectin type III domaincontaining protein 5 (FNDC5), which both are involved in the upregulation of BDNF expression. Wrann et al. (2013) in an interesting study in mice demonstrated that, aerobic exercise causes production of PGC- $1 \alpha$ in muscles, and then PGC- $1 \alpha$ induces FNDC5. Then irisin is released by the cleavage of FNDC5 (Lee et al., 2012; Miyamoto-Mikami et al., 2015; Lourenco et al., 2019) and induces BDNF expression through inhibition of histone deacetylase-1, both in human and animal studies (Erickson et al., 2009; Koppel and Timmusk, 2013).

Finally, sustained BDNF levels during exercise, have important roles in cognition through stimulating long-term potentiation, protein phosphorylation, synaptic regeneration (Ji et al., 2005; Tapia-Arancibia et al., 2008), and finally memory improvement in healthy and AD model of rats (Wu et al., 2008; Griffin et al., 2009; Babaei, 2021).

Besides neurotrophic effects which have been discussed above, BDNF also exerts metabotropic roles, and indirectly could influence memory and learning ability, via alleviating systemic insulin resistance in men with MetS (Damirchi et al., 2014), and mitochondrial biogenesis in cultured murine hippocampal neurons (Cheng et al., 2012).

Given the importance of BDNF levels on neuroplasticity and memory, these results support that exercise should be considered as part of rehabilitation programs in different neurodegenerative disorders.

\section{Insulin-Like Growth Factor-1}

Insulin-like growth factor (IGF-I), is a peptide which is secreted by liver and some other tissues, and stimulates bone growth, and decreases blood glucose levels (Utiger, 2011). Alteration in IGF-I levels, in response to exercise training has inconsistent results in old adults, with or without mild cognitive impairment (Baker et al., 2010; Anderson-Hanley et al., 2017; Tsai C.-L. et al., 2018; Liu et al., 2020; Arazi et al., 2021). Inconsistent results, probably related to various protocols of biochemical assessments, or subjects characteristics. For example, no significant change was found after neither strength nor aerobic exercise in demented patients (Liu et al., 2020). Also a negative correlation was found between endurance exercise and cognitive prognosis when serum IGF-I levels were above $74 \mathrm{ng} / \mathrm{ml}$ by Vardy et al. (2007) and Anderson-Hanley et al. (2017). These authors concluded that the higher IGF-I levels, might indicate disease progression, potentially as a compensatory response similar to the higher BDNF levels in metabolic syndrome (Damirchi et al., 2014). Therefore, participants with higher IGF-I levels, may be less likely to benefit from the exercise intervention in either healthy adults or adults with Alzheimer's disease (Vardy et al., 2007; Anderson-Hanley et al., 2017).

Also increase in both central and peripheral IGF-1 levels following exercise training in rodents (Carro et al., 2000; Trejo et al., 2001; Nakajima et al., 2010; Kim et al., 2019) have been reported. Finally, IGF-1 increases the expression of BDNF (Carro et al., 2000), synaptic plasticity markers such as synaptophysin and postsynaptic density protein-95 in the hippocampus, and represents positive effects on the spatial and aversive memories in healthy rats (Segabinazi et al., 2020).

\section{Neurotransmitters (Adrenaline)}

Circulatory catecholamines levels have been shown to be increased during exercise training (Kraemer et al., 1999; Sutoo and Akiyama, 2003), and their levels are related to better intermediate and long-term retentions of memory (Winter et al., 2007). Adrenaline is released from the adrenal gland in response to exercise (Kjær, 1998), and has been studied more than other bioamines. Since adrenaline does not cross the BBB (Bradbury, 1993); therefore, it might indirectly affect the brain via activating the vagal nerve (McGaugh et al., 1996), then stimulates noradrenergic inputs of the amygdala (Williams et al., 2000; Miyashita and Williams, 2006), hippocampus (Miyashita and Williams, 2004), and locus coeruleus (Miyashita and Williams, 2006); the main source of brain noradrenaline (McMorris, 2016). Noradrenaline released by locus coeruleus, modulates memory and learning following exercise training both in human (Atzori et al., 2016; Chandler, 2016; Feinstein et al., 2016), and animal studies (Mello-Carpes and Izquierdo, 2013; da Silva de Vargas et al., 2017). Together, these findings suggest an exercise-induced increase of noradrenaline potentiating role on learning and memory.

\section{Endocannabinoid}

The endocannabinoid system (ECS) is a system of biological lipids, that essentially modulates the functions of the immune, endocrine, and nervous systems (Lu and Mackie, 2016; Zou and Kumar, 2018). In the brain, ECS is involved in various neurophysiological processes including neurogenesis, synaptic plasticity, as well as memory, and emotions (Bisogno and Di Marzo, 2008; Silvestri and Di Marzo, 2013).

Several studies showed that, both acute physical activity (Brellenthin et al., 2017) and regular aerobic exercise, raise endocannabinoid (EC) levels in healthy adults and animal models (Alkadhi, 2018), and elevated plasma levels of EC are potentially associated with long-term beneficial effects on memory and neural plasticity in healthy or adults with major depressive disorders (Coccaro et al., 2018; Stone et al., 2018; Meyer et al., 2019). Moreover, EC reduce anxiety, neuroinflammation, oxidative stress, and brain amyloid-beta deposition (Charytoniuk et al., 2020).

Not only the intensity of physical activity determines the alteration of EC in healthy adults (Feuerecker et al., 2012), but also the duration and subjects characteristics are important as well (Charytoniuk et al., 2020). Some studies showed that chronic exercises might be associated with the upregulation of EC receptor (CB1R) in the hippocampus of mice (FerreiraVieira et al., 2014; Brellenthin and Koltyn, 2016). Interestingly, a recent study revealed that isometric handgrip exercise for 3 min, led to major alterations in the EC and its receptor type 1 (Crombie et al., 2017).

Importantly, EC have been known to express BDNF (Sleiman et al., 2016), and then, BDNF regulates the expression of CB1 receptor as well (Maison et al., 2009). In fact, CB1 receptor signaling in glutamatergic neurons increases the BDNF production, and dendritic spine density in the hippocampus and leads to long-term memory in CB1R deficient mice (Wang and Han, 2020). 
Consequently, exercise-increased EC and BNDF levels, synergistically improve memory recall and storage in healthy men (Marin Bosch et al., 2021).

$\mathrm{Wu}$ et al. (2020) provide new insights into the BDNF/ECassociated modulation of neurotransmission, in the physiological and pathologic processes. They stated that BDNF inhibits the excitatory postsynaptic current (EPSC), presynaptic calcium influx, and exocytosis/endocytosis via activation of the presynaptic $\mathrm{CB} 1$ receptors. They also found that BDNF induces the release of endocannabinoids and also retrogradely activates presynaptic CB1Rs via postsynaptic TrkB receptors (Wu et al., 2020).

In this regard, Ferreira et al. (2018) demonstrated that endogenous BDNF is crucial for the cannabinoid-mediated effects on the subventricular zone and dentate gyrus neurogenesis. On the other hand, cannabinoid receptor signaling is also determinant for BDNF actions upon neurogenesis (Ferreira et al., 2018).

Moreover, BDNF attenuates inhibitory transmission by inducing the postsynaptic release of EC, that retrogradely suppress GABA release in the somatosensory cortex (Yeh et al., 2017; Selvam et al., 2018).

Nevertheless, the mutual relationship between physical activity, the endocannabinoid system, and memory performance remains not well discovered and needs proper fulfillment.

\section{Myokines}

Contracted skeletal muscles following exercise leads to the secretion of various paracrine factors, which are named myokines. Myokines include irisin, myonectin, angiopoietin-like protein (ANGPTL), $\beta$-aminoisobutyric acid, fibroblast growth factor 21 (FGF21) (Ingerslev et al., 2017; Cinkajzlová et al., 2018). Myokines are linked with other physiological systems and might impact on their functionality/(Pedersen, 2013; Whitham and Febbraio, 2016). For instance, irisin is a peptide secreted by skeletal muscles, particularly after intermittent high-intensity exercise, and is correlated with glucose and lipids metabolism in skeletal muscles in healthy adults (Huh et al., 2014). Besides metabolic roles, irisin might coordinate locomotion following exercising in healthy rat model (Zhang et al., 2015). Moreover, irisin elevation has been known to be associated with secretion of BDNF, metabolic alterations in human subjects (Huang L. et al., 2019; Arazi et al., 2021), and also facilitation of memory retrieval in male rats (Ding et al., 2006; Babaei et al., 2019). In contrast, finding no correlation between irisin, BDNF, and memory in metabolic syndrome model of rats, indicates that irisin might not be the only mediator for exercise on learning and memory in pathologic conditions such as metabolic syndrome (Babaei et al., 2017).

Another myokine that is elevated after exercise is myonectin. Myonektin is secreted by skeletal muscles and adipose tissue, and induces uptake and oxidation of glucose and fatty acid in healthy adults (Toloza et al., 2018), in response to exercise (Seldin et al., 2012; Toloza et al., 2018). The extent of muscle mass loss and elevated level of myonectin is associated with the severity of cognitive deficits in the Alzheimer's disease model of mice (Lin et al., 2019).
Since the direct effects of myokines on memory have not been understood yet, here we consider their indirect effects on memory via insulin sensitivity.

\section{Improving Insulin Sensitivity}

Metabolic syndrome is a complex condition characterized by insulin resistance, hyperglycemia, dyslipidemia, and obesity (Alonso-Gómez et al., 2019), and stands as a risk factor for cognitive decline and Alzheimer's disease (Razay et al., 2007; Farooqui et al., 2012; Neergaard et al., 2017; Kong et al., 2018). One of the features of metabolic syndrome, is the excess visceral fats producing inflammatory cytokines which are named adipokines. Adipokines are categorized into two groups of pro and anti-inflammatory. Pro-inflammatory adipokines cause oxidative stress and increase inflammation, which consequently leads to memory impairment (Santilli et al., 2017; Funcke and Scherer, 2019). On the other hand, exercise has been known to reduce pro-inflammatory, but increase anti-inflammatory adipokines and prevents the progression of metabolic syndrome toward type II diabetes (Babaei et al., 2015). In addition, besides alteration in adipokine levels, exercise alleviates cognitive decline in middle-aged men with metabolic syndrome (Damirchi et al., 2014), by epigenetic modulation in cell metabolism (Sjøberg et al., 2017). For instance, the first beneficial effect of exercise or lipolytic action involves the phosphorylation and activation of AMPK in healthy mice (Huang J. et al., 2019; Yoon et al., 2019). AMPK is a fuel-sensing enzyme, which is activated after the increase in the cellular ratio of AMP relative to ATP. Animal studies on healthy mice revealed that AMPK also mediates mitochondrial biogenesis (Jørgensen et al., 2007), angiogenesis (Ouchi et al., 2005), BDNF production, and therefore reverse memory deficits (Kim and Leem, 2016). Moreover, exercise directly activates the autophagy through up-regulating the AMPK-SIRT1 signaling pathway (Huang J. et al., 2019), and remove abnormal proteins responsible for neurodegenerative diseases in mouse (Osellame and Duchen, 2014; Lin et al., 2020). Elevated AMPK exerts insulin sensitivity in healthy rats (Zhang et al., 2011), thus attenuates the progression of neurodegeneration in human and animal models with $\mathrm{AD}$ (Watson and Craft, 2004).

The second beneficial effect of exercise, takes place via activating phosphoinositide 3-kinase and translocating the glucose transporter type 4 into the skeletal muscles (Vega et al., 2017), and the third mechanism mediated by adipokines (Beavers et al., 2010). One of the pro-inflammatory adipokines, is TNF$\alpha$ which leads to insulin resistance, and induces a chronic state of local inflammation in rats with diabetes or metabolic syndrome (Samarghandian et al., 2016; Kouhestani et al., 2018). TNF- $\alpha$ also contributes to cognitive decline in $\mathrm{AD}$ patients by elevating oxidative stress and apoptosis (Perry et al., 2007; Janelsins et al., 2008). Both aerobic and exercise training have been demonstrated to be efficient in reducing TNF- $\alpha$ in young adults and suppressing neuroinflammation (Flynn et al., 2003; Forti et al., 2017; Monteiro-Junior et al., 2018).

On the other hand, reduction in anti-inflammatory adipokines, more notably, adiponectin is associated with metabolic syndrome in a rat model (Damirchi et al., 2010), 
coronary heart disease in adult patients (Lindberg et al., 2017), and cognitive decline in adults with AD (Teixeira et al., 2013). Adiponectin receptor-1 knockdown mice exhibited spatial learning and memory impairment (Kim et al., 2017), however exercise training exerts anti-inflammatory and insulin-sensitizing effects via elevating adiponectin and inhibiting TNF $\alpha$ and IL-6 (Tore et al., 2007; Rizzo et al., 2020). Administration of exogen adiponectin improves learning and memory (Tore et al., 2007), similar to the exercise-induced elevated adiponectin level (Martinez-Huenchullan et al., 2018; Pousti et al., 2018; Diniz et al., 2019; Parastesh et al., 2019) in animal studies.

Considering more than 800 adipokines, it needs more studies to clarify the exact roles of these molecules on memory following exercise training.

\section{Epigenetic Mechanisms}

Acute and regular exercise training induces both short and longterm epigenetic regulations, creating a "functional genome" that consequently leads to adaptation during the active life span of individuals. For example, memory-boosting effects of exercise training could be partly mediated by DNA methylation (Deibel et al., 2015; Kim and Kaang, 2017), histone acetylation (Barrett and Wood, 2008; Fernandes et al., 2017), as well as up and downregulation of microRNA (Fernandes et al., 2017; Grazioli et al., 2017). Recently, an increase in histone acetylation of the BDNF and the expression of immediate early genes of $c$-fos and $A r c$, parallel with improvement in plasticity and memory consolidation, storage, and retrieval in senescence-accelerated mice following aerobic exercise have been reported (Maejima et al., 2018, 2021).

In contrast with regular exercise training, an acute exercise had no significant epigenetic change in basal levels of plasma BDNF considering histone acetylation in healthy amateur runners (da Silveira et al., 2017).

Taken altogether, epigenetic modification of exercise is incomplete, and needs to be evaluated considering different protocols timing and new candidate genes.

\section{MicroRNAs}

MicroRNAs (miRNAs) are small, single-strand non-coding RNAs that play pivotal roles in the post-transcriptional regulation of genes responsible for various physiological functions (Baek et al., 2008). A growing body of evidence in human and animal studies has shown that exercise alters blood levels of several miRNAs (Flowers et al., 2015; Gomes et al., 2015; Xu et al., 2015), and these small molecules modulate communication between the brain and muscles. However, the patterns of miRNAs regulation in response to exercise training is very complicated. Some of them are upregulated in response to acute exercise (miR-146a, miR222 ), but some are increased in response to sustained training (miRNA-20), and other remain non-responsive (miR-133a, miR210, and miR-328) (Baggish et al., 2011). One of the broadly studied miRNA in response to exercise is miR-132. This mi RNA is involved in memory formation and synaptic plasticity (Scott et al., 2012; Hansen et al., 2013; Wang et al., 2013). For instance, Radom-Aizik et al. (2012) reported a rapid elevation in circulating levels of miR-132 in healthy men in response to an acute intermittent exercise, but a reduction in trained human subjects (de Gonzalo-Calvo et al., 2015, 2018). Meanwhile, an animal study carried out by Dong et al. (2018) showed increased miR-132 level in the hippocampus of the mouse model of $\mathrm{AD}$ after aerobic exercise, parallel with memory improvement. In contradictory, Smith et al. (2015) and Hernandez-Rapp et al. (2016) reported a reduction in the expression of miR132 in the transgenic mice model of $\mathrm{AD}$. The inconsistency in literature, might be related to the model and stages of $\mathrm{AD}$ development, and also the sensitivity of biochemical assessments used for mi RNA.

In conclusion, exercise training could mitigate the aginginduced memory decline by regulating the hippocampal expression of miR-132 in the AD mice model (Dong et al., 2018), miR-21 in mice with traumatic brain injury (Hu et al., 2015), miR$34 \mathrm{a}$ and miR-124 in rats with cognitive impairment (Pan-Vazquez et al., 2015; Kou et al., 2017).

Taken all together, it seems the bioinformatic analysis is required to summarize the panel of various miRNA in response to exercise training, rather than a single molecule.

\section{CONCLUSION}

In conclusion, this review provides an affordable and effective method to improve cognitive function in all ages, particularly the elderly who are most vulnerable to neurodegenerative disorders. In spite of the limitations of this review, it is suggested that frequent moderate aerobic activity is associated with improved neurocognitive performance for elderly people. Improved brain circulation, neurotrophic factors, mitochondrial biogenesis, and the release of numerous signaling molecules, including myokines and adipokines in response to regular exercise might be involved in the neuroprotective mechanisms of exercise training. Currently, among various mechanisms, irisin/BDNF signaling seems to stand at the core of exercise facilitatory effects on learning and memory. These molecular signalings anticipate better understanding of mechanisms that will enable the development of pharmaceuticals, particularly for those who are activity limited (coma, spinal cord injury, etc.).

The strengths of this review is describing updated findings on various exercise modalities and memory performance which uncovers molecular and cellular linkages critical in studies of aging and neurodegeneration. However, the limitations of the present review are focusing only on the selected possible mechanisms including some of the important mediators and signaling pathways.

Future studies need to find standard protocol for exercise intensity, and also adequate follow-ups to consider the maintenance of neurocognitive effects of exercise.

\section{AUTHOR CONTRIBUTIONS}

PB participated in the design and coordination of the manuscript, drafted, and revised it. HA participated in drafting 
the manuscript and managing references, providing the graphical abstract. Both authors have read and approved the final version of the manuscript and agreed with the order of presentation of the authors.

\section{REFERENCES}

Adlard, P. A., Perreau, V. M., Pop, V., and Cotman, C. W. (2005). Voluntary exercise decreases amyloid load in a transgenic model of Alzheimer's disease. J. Neurosci. 25, 4217-4221. doi: 10.1523/JNEUROSCI.0496-05.2005

Aguiar, A. S., Tuon, T., Soares, F. S., da Rocha, L. G. C., Silveira, P. C., and Pinho, R. A. (2008). The effect of n-acetylcysteine and deferoxamine on exerciseinduced oxidative damage in striatum and hippocampus of mice. Neurochem. Res. 33, 729-736. doi: 10.1007/s11064-007-9485-8

Alkadhi, K. A. (2018). Exercise as a positive modulator of brain function. Mol. Neurobiol. 55, 3112-3130. doi: 10.1007/s12035-017-0516-4

Alonso-Gómez, A. M., Sierra, L. T., Frau, E. F., Güemez, L. G., Uribarri, A. A., Portillo, M. P., et al. (2019). Diastolic dysfunction and exercise capacity in patients with metabolic syndrome and overweight/obesity. Int. J. Cardiol. Heart Vasc. 22, 67-72. doi: 10.1016/j.ijcha.2018.12.010

Amjad, I., Toor, H., Niazi, I. K., Afzal, H., Jochumsen, M., Shafique, M., et al. (2019). Therapeutic effects of aerobic exercise on EEG parameters and higher cognitive functions in mild cognitive impairment patients. Int. J. Neurosci. 129, 551-562.

Anderson-Hanley, C., Maloney, M., Barcelos, N., Striegnitz, K., and Kramer, A. (2017). Neuropsychological benefits of neuro-exergaming for older adults: a pilot study of an interactive physical and cognitive exercise system (iPACES). J. Aging Phys. Act. 25, 73-83.

Arazi, H., Babaei, P., Moghimi, M., and Asadi, A. (2021). Acute effects of strength and endurance exercise on serum BDNF and IGF-1 levels in older men. BMC Geriatr. 21:50. doi: 10.1186/s12877-020-01937-6

Atzori, M., Cuevas-Olguin, R., Esquivel-Rendon, E., Garcia-Oscos, F., SalgadoDelgado, R. C., Saderi, N., et al. (2016). Locus ceruleus norepinephrine release: a central regulator of CNS spatio-temporal activation? Front. Synaptic Neurosci. 8:25. doi: 10.3389/fnsyn.2016.00025

Babaei, P. (2021). NMDA and AMPA receptors dysregulation in Alzheimer's disease. Eur. J. Pharmacol. 908:174310. doi: 10.1016/j.ejphar.2021.174310

Babaei, P., Damirchi, A., and Azali Alamdari, K. (2013). Effects of endurance training and detraining on serum BDNF and memory performance in middle aged males with metabolic syndrome. Iran. J. Endocrinol. Metab. 15, 132-142.

Babaei, P., Damirchi, A., Mehdipoor, M., and Tehrani, B. S. (2014). Long term habitual exercise is associated with lower resting level of serum BDNF. Neurosci. Lett. 566, 304-308. doi: 10.1016/j.neulet.2014.02.011

Babaei, P., Mojtabavi, K., and Kouhestani, S. (2019). The Effect of intrahippocampal injection of insulin-like growth factor-1 on morphineinduced amnesia in wistar rats. J. Kerman Univ. Med. Sci. 26, $185-191$.

Babaei, P., Pourrahim Ghouroghchi, A., Damirchi, A., and Soltani Tehrani, B. (2015). The interactive effect of aerobic-resistance training and estrogen therapy on metabolic syndrome indices and omentin-1. Physiol. Pharmacol. 19, 200-207.

Babaei, P., Shirkouhi, S. G., Hosseini, R., and Soltani Tehrani, B. (2017). Vitamin $\mathrm{D}$ is associated with metabotropic but not neurotrophic effects of exercise in ovariectomized rats. Diabetol. Metab. Syndr. 9:91. doi: 10.1186/s13098-0170288-z

Baek, D., Villén, J., Shin, C., Camargo, F. D., Gygi, S. P., and Bartel, D. P. (2008). The impact of microRNAs on protein output. Nature 455, 64-71. doi: 10.1038/ nature 07242

Baggish, A. L., Hale, A., Weiner, R. B., Lewis, G. D., Systrom, D., Wang, F., et al. (2011). Dynamic regulation of circulating microRNA during acute exhaustive exercise and sustained aerobic exercise training. J. Physiol. 589, 3983-3994. doi: 10.1113/jphysiol.2011.213363

Baker, L. D., Frank, L. L., Foster-Schubert, K., Green, P. S., Wilkinson, C. W., McTiernan, A., et al. (2010). Effects of aerobic exercise on mild cognitive impairment: a controlled trial. Arch. Neurol. 67, 71-79.

Ball, L. J., and Birge, S. J. (2002). Prevention of brain aging and dementia. Clin. Geriatr. Med. 18, 485-503. doi: 10.1016/s0749-0690(02)00027-7

\section{ACKNOWLEDGMENTS}

We express gratitude to our students, athletes and all participants in our studies, who helped to develop this idea.

Barrett, R. M., and Wood, M. A. (2008). Beyond transcription factors: the role of chromatin modifying enzymes in regulating transcription required for memory. Learn. Mem. 15, 460-467. doi: 10.1101/lm.917508

Beavers, K. M., Hsu, F.-C., Isom, S., Kritchevsky, S. B., Church, T., Goodpaster, B., et al. (2010). Long-term physical activity and inflammatory biomarkers in older adults. Med. Sci. Sports Exerc. 42:2189. doi: 10.1249/MSS.0b013e3181e3ac80

Belviranli, M., Okudan, N., Kabak, B., Erdoğan, M., and Karanfilci, M. (2016). The relationship between brain-derived neurotrophic factor, irisin and cognitive skills of endurance athletes. Phys. Sportsmed. 44, 290-296. doi: 10.1080/ 00913847.2016.1196125

Bishop, D. J., Botella, J., Genders, A. J., Lee, M. J., Saner, N. J., Kuang, J., et al. (2019). High-Intensity exercise and mitochondrial biogenesis: current controversies and future research directions. Physiology (Bethesda) 34, 56-70. doi: 10.1152/ physiol.00038.2018

Bisogno, T., and Di Marzo, V. (2008). The role of the endocannabinoid system in Alzheimer's disease: facts and hypotheses. Curr. Pharm. Des. 14, 2299-3305. doi: $10.2174 / 138161208785740027$

Bradbury, M. W. (1993). The blood-brain barrier. Exp. Physiol. 78, 453-472. doi: 10.1113/expphysiol.1993.sp003698

Brellenthin, A. G., and Koltyn, K. F. (2016). Exercise as an adjunctive treatment for cannabis use disorder. Am. J. Drug Alcohol Abuse 42, 481-489. doi: 10.1080/ 00952990.2016.1185434

Brellenthin, A. G., Crombie, K. M., Hillard, C. J., and Koltyn, K. F. (2017). Endocannabinoid and mood responses to exercise in adults with varying activity levels. Med. Sci. Sports Exerc. 49, 1688-1696. doi: 10.1249/mss. 0000000000001276

Brisswalter, J., Collardeau, M., and René, A. (2002). Effects of acute physical exercise characteristics on cognitive performance. Sports Med. 32, 555-566.

Buchman, A. S., Boyle, P. A., Yu, L., Shah, R. C., Wilson, R. S., and Bennett, D. A. (2012). Total daily physical activity and the risk of AD and cognitive decline in older adults. Neurology 78, 1323-1329. doi: 10.1212/WNL.0b013e3182535d35

Bue-Estes, C. L., Willer, B., Burton, H., Leddy, J. J., Wilding, G. E., and Horvath, P. J. (2008). Short-term exercise to exhaustion and its effects on cognitive function in young women. Percept. Motor Skills 107, 933-945. doi: 10.2466/pms.107.7. 933-945

Burdette, J. H., Laurienti, P. J., Espeland, M. A., Morgan, A. R., Telesford, Q., Vechlekar, C. D., et al. (2010). Using network science to evaluate exerciseassociated brain changes in older adults. Front. Aging Neurosci. 2:23. doi: 10. 3389/fnagi.2010.00023

Burtscher, J., Millet, G. P., Place, N., Kayser, B., and Zanou, N. (2021). The muscle-brain axis and neurodegenerative diseases: the key role of mitochondria in exercise-induced neuroprotection. Int. J. Mol. Sci. 22, 6479. doi: 10.3390/ ijms 22126479

Burzynska, A. Z., Wong, C. N., Voss, M. W., Cooke, G. E., Gothe, N. P., Fanning, J., et al. (2015). Physical activity is linked to greater moment-to-moment variability in spontaneous brain activity in older adults. PLoS One 10:e0134819. doi: 10.1371/journal.pone.0134819

Carro, E., Nuñez, A., Busiguina, S., and Torres-Aleman, I. (2000). Circulating insulin-like growth factor I mediates effects of exercise on the brain. J. Neurosci. 20, 2926-2933. doi: 10.1523/jneurosci.20-08-02926.2000

Caspersen, C. J., Powell, K. E., and Christenson, G. M. (1985). Physical activity, exercise, and physical fitness: definitions and distinctions for health-related research. Public Health Rep. 100:126.

Castellano, C. A., Paquet, N., Dionne, I. J., Imbeault, H., Langlois, F., Croteau, E., et al. (2017). A 3-month aerobic training program improves brain energy metabolism in mild Alzheimer's disease: preliminary results from a neuroimaging study. J. Alzheimers Dis. 56, 1459-1468. doi: 10.3233/jad161163

Chandler, D. J. (2016). Evidence for a specialized role of the locus coeruleus noradrenergic system in cortical circuitries and behavioral operations. Brain Res. 1641, 197-206. doi: 10.1016/j.brainres.2015.11.022 
Chang, M., Jonsson, P. V., Snaedal, J., Bjornsson, S., Saczynski, J. S., Aspelund, T., et al. (2010). The effect of midlife physical activity on cognitive function among older adults: AGES-Reykjavik study. J. Gerontol. Ser. A 65A, 1369-1374. doi: 10.1093/gerona/glq152

Chang, Y. K., Labban, J. D., Gapin, J. I., and Etnier, J. L. (2012). The effects of acute exercise on cognitive performance: a meta-analysis. Brain Res. 1453, 87-101. doi: 10.1016/j.brainres.2012.02.068

Charytoniuk, T., Zywno, H., Konstantynowicz-Nowicka, K., Berk, K., Bzdega, W., and Chabowski, A. (2020). Can physical activity support the endocannabinoid system in the preventive and therapeutic approach to neurological disorders? Int. J. Mol. Sci. 21:4221. doi: 10.3390/ijms21124221

Cheng, A., Wan, R., Yang, J.-L., Kamimura, N., Son, T. G., Ouyang, X., et al. (2012). Involvement of PGC-1 $\alpha$ in the formation and maintenance of neuronal dendritic spines. Nat. Commun. 3:1250.

Chieffi, S., Messina, G., Villano, I., Messina, A., Valenzano, A., Moscatelli, F., et al. (2017). Neuroprotective effects of physical activity: evidence from human and animal studies. Front. Neurol. 8:188. doi: 10.3389/fneur.2017.00188

Chirles, T. J., Reiter, K., Weiss, L. R., Alfini, A. J., Nielson, K. A., and Smith, J. C. (2017). Exercise training and functional connectivity changes in mild cognitive impairment and healthy elders. J. Alzheimers Dis. 57, 845-856. doi: 10.3233/JAD-161151

Cinkajzlová, A., Mráz, M., Lacinová, Z., Kloučková, J., Kaválková, P., Kratochvílová, H., et al. (2018). Angiopoietin-like protein 3 and 4 in obesity, type 2 diabetes mellitus, and malnutrition: the effect of weight reduction and realimentation. Nutr. Diabetes 8:21.

Clark, I. A., Callaghan, M. F., Weiskopf, N., and Maguire, E. A. (2021). The relationship between hippocampal-dependent task performance and hippocampal grey matter myelination and iron content. Brain Neurosci. Adv. 5:23982128211011923. doi: 10.1177/23982128211011923

Clark, J., and Simon, D. K. (2009). Transcribe to survive: transcriptional control of antioxidant defense programs for neuroprotection in Parkinson's disease. Antioxid. Redox Signal. 11, 509-528. doi: 10.1089/ars.2008.2241

Coccaro, E. F., Hill, M. N., Robinson, L., and Lee, R. J. (2018). Circulating endocannabinoids and affect regulation in human subjects. Psychoneuroendocrinology 92, 66-71. doi: 10.1016/j.psyneuen.2018.03.009

Coco, M., Alagona, G., Rapisarda, G., Costanzo, E., Calogero, R. A., Perciavalle, V., et al. (2010). Elevated blood lactate is associated with increased motor cortex excitability. Somatosens. Motor Res. 27, 1-8. doi: 10.3109/08990220903471765

Colcombe, S., and Kramer, A. F. (2003). Fitness effects on the cognitive function of older adults: a meta-analytic study. Psychol. Sci. 14, 125-130. doi: 10.1111/ 1467-9280.t01-1-01430

Cooper-Kahn, J. D., and Laurie, C. (2008). What is Executive Functioning? [Online]. Available online at: http://www.ldonline.org/article/ 29122/?fbclid=IwAR26iyWjG_PavocNG5bkg1L2pXC_P6XgP5NuOJVYfzb5x99IFGHP8ZONVA\&theme=print (accessed October 19, 2021).

Covassin, T., Weiss, L., Powell, J., and Womack, C. (2007). Effects of a maximal exercise test on neurocognitive function. Br. J. Sports Med. 41, 370-374. doi: 10.1136/bjsm.2006.032334

Crombie, K. M., Brellenthin, A. G., Hillard, C. J., and Koltyn, K. F. (2017). Endocannabinoid and opioid system interactions in exercise-induced hypoalgesia. Pain Med. 19, 118-123. doi: 10.1093/pm/pnx058

da Silva de Vargas, L., Neves, B. S. D., Roehrs, R., Izquierdo, I., and MelloCarpes, P. (2017). One-single physical exercise session after object recognition learning promotes memory persistence through hippocampal noradrenergic mechanisms. Behav. Brain Res. 329, 120-126. doi: 10.1016/j.bbr.2017.04.050

da Silveira, F. P., Basso, C., Raupp, W., Dalpiaz, M., Bertoldi, K., Siqueira, I. R., et al. (2017). BDNF levels are increased in peripheral blood of middle-aged amateur runners with no changes on histone $\mathrm{H} 4$ acetylation levels. J. Physiol. Sci. 67, 681-687. doi: 10.1007/s12576-016-0496-6

Damirchi, A., Babaei, P., Gholamali, M., and Ranjbar, K. (2012). "Mitochondrial biogenesis in skeletal muscle: exercise and aging," in Skeletal Muscle-From Myogenesis to Clinical Relations, ed. J. Cseri (London: IntechOpen).

Damirchi, A., Hosseini, F., and Babaei, P. (2018). Mental training enhances cognitive function and BDNF more than either physical or combined training in elderly women with MCI: a small-scale study. Am. J. Alzheimers Dis. Other Dement. 33, 20-29. doi: 10.1177/1533317517727068

Damirchi, A., Mehdizade, R., Ansar, M., Soltani, B., and Babaei, P. (2010). Effects of aerobic exercise training on visceral fat and serum adiponectin concentration in ovariectomized rats. Climacteric 13, 171-178. doi: 10.3109/136971309033 60234

Damirchi, A., Tehrani, B. S., Alamdari, K. A., and Babaei, P. (2014). Influence of aerobic training and detraining on serum BDNF, insulin resistance, and metabolic risk factors in middle-aged men diagnosed with metabolic syndrome. Clin. J. Sport Med. 24, 513-518. doi: 10.1097/JSM.0000000000000082

de Gonzalo-Calvo, D., Dávalos, A., Fernández-Sanjurjo, M., Amado-Rodríguez, L., Díaz-Coto, S., Tomás-Zapico, C., et al. (2018). Circulating microRNAs as emerging cardiac biomarkers responsive to acute exercise. Int. J. Cardiol. 264, 130-136. doi: 10.1016/j.ijcard.2018.02.092

de Gonzalo-Calvo, D., Dávalos, A., Montero, A., García-González, Á, Tyshkovska, I., González-Medina, A., et al. (2015). Circulating inflammatory miRNA signature in response to different doses of aerobic exercise. J. Appl. Physiol. 119, 124-134. doi: 10.1152/japplphysiol.00077.2015

Deibel, S. H., Zelinski, E. L., Keeley, R. J., Kovalchuk, O., and McDonald, R. J. (2015). Epigenetic alterations in the suprachiasmatic nucleus and hippocampus contribute to age-related cognitive decline. Oncotarget 6, 23181-23203. doi: 10.18632 /oncotarget. 4036

Delezie, J., and Handschin, C. (2018). Endocrine crosstalk between skeletal muscle and the brain. Front. Neurol. 9:698. doi: 10.3389/fneur.2018.00698

Di Liegro, C. M., Schiera, G., Proia, P., and Di Liegro, I. (2019). Physical activity and brain health. Genes 10:720.

Diamond, A. (2013). Executive functions. Annu. Rev. Psychol. 64, 135-168.

Ding, Q., Vaynman, S., Souda, P., Whitelegge, J. P., and Gomez-Pinilla, F. (2006). Exercise affects energy metabolism and neural plasticity-related proteins in the hippocampus as revealed by proteomic analysis. Eur. J. Neurosci. 24, 1265-1276. doi: 10.1111/j.1460-9568.2006.05026.x

Diniz, T. A., Aquino Júnior, J. C. J., Mosele, F. C., Cabral-Santos, C., Lima Junior, E. A., Teixeira, A. A. S., et al. (2019). Exercise-induced AMPK activation and IL-6 muscle production are disturbed in adiponectin knockout mice. Cytokine 119, 71-80. doi: 10.1016/j.cyto.2019.03.009

Dong, J., Liu, Y., Zhan, Z., and Wang, X. (2018). MicroRNA-132 is associated with the cognition improvement following voluntary exercise in SAMP8 mice. Brain Res. Bull. 140, 80-87. doi: 10.1016/j.brainresbull.2018.04.007

Duzel, E., van Praag, H., and Sendtner, M. (2016). Can physical exercise in old age improve memory and hippocampal function? Brain 139, 662-673. doi: 10.1093/brain/awv407

El Hayek, L., Khalifeh, M., Zibara, V., Abi Assaad, R., Emmanuel, N., Karnib, N., et al. (2019). Lactate mediates the effects of exercise on learning and memory through SIRT1-dependent activation of hippocampal brain-derived neurotrophic factor (BDNF). J. Neurosci. 39, 2369-2382. doi: 10.1523/jneurosci. 1661-18.2019

Elahi, M., Motoi, Y., Matsumoto, S.-E., Hasan, Z., Ishiguro, K., and Hattori, N. (2016). Short-term treadmill exercise increased tau insolubility and neuroinflammation in tauopathy model mice. Neurosci. Lett. 610, 207-212. doi: 10.1016/j.neulet.2015.11.010

Erickson, K. I., Miller, D. L., Weinstein, A. M., Akl, S. L., and Banducci, S. (2012). Physical activity and brain plasticity in late adulthood: a conceptual and comprehensive review. Ageing Res. 3:e6.

Erickson, K. I., Prakash, R. S., Voss, M. W., Chaddock, L., Heo, S., McLaren, M., et al. (2010). Brain-derived neurotrophic factor is associated with agerelated decline in hippocampal volume. J. Neurosci. 30, 5368-5375. doi: 10. 1523/JNEUROSCI.6251-09.2010

Erickson, K. I., Prakash, R. S., Voss, M. W., Chaddock, L., Hu, L., Morris, K. S., et al. (2009). Aerobic fitness is associated with hippocampal volume in elderly humans. Hippocampus 19, 1030-1039. doi: 10.1002/hipo.20547

Erickson, K. I., Voss, M. W., Prakash, R. S., Basak, C., Szabo, A., Chaddock, L., et al. (2011). Exercise training increases size of hippocampus and improves memory. Proc. Natl. Acad. Sci. U.S.A. 108, 3017-3022. doi: 10.1073/pnas.1015950108

Farooqui, A. A., Farooqui, T., Panza, F., and Frisardi, V. (2012). Metabolic syndrome as a risk factor for neurological disorders. Cell. Mol. Life Sci. 69, 741-762.

Feinstein, D. L., Kalinin, S., and Braun, D. (2016). Causes, consequences, and cures for neuroinflammation mediated via the locus coeruleus: noradrenergic signaling system. J. Neurochem. 139, 154-178. doi: 10.1111/jnc.13447

Fernandes, J., Arida, R. M., and Gomez-Pinilla, F. (2017). Physical exercise as an epigenetic modulator of brain plasticity and cognition. Neurosci. Biobehav. Rev. 80, 443-456. doi: 10.1016/j.neubiorev.2017.06.012 
Ferreira, F. F., Ribeiro, F. F., Rodrigues, R. S., Sebastião, A. M., and Xapelli, S. (2018). Brain-Derived neurotrophic factor (BDNF) role in cannabinoidmediated neurogenesis. Front. Cell. Neurosci. 12:441. doi: 10.3389/fncel.2018. 00441

Ferreira-Vieira, T. H., Bastos, C. P., Pereira, G. S., Moreira, F. A., and Massensini, A. R. (2014). A role for the endocannabinoid system in exercise-induced spatial memory enhancement in mice. Hippocampus 24, 79-88. doi: 10.1002/hipo. 22206

Feter, N., Alt, R., Dias, M., and Rombaldi, A. (2019). How do different physical exercise parameters modulate brain-derived neurotrophic factor in healthy and non-healthy adults? A systematic review, meta-analysis and meta-regression. Sci. Sports 34, 293-304.

Feuerecker, M., Hauer, D., Toth, R., Demetz, F., Hölzl, J., Thiel, M., et al. (2012). Effects of exercise stress on the endocannabinoid system in humans under field conditions. Eur. J. Appl. Physiol. 112, 2777-2781. doi: 10.1007/s00421-0112237-0

Firth, J., Stubbs, B., Vancampfort, D., Schuch, F., Lagopoulos, J., Rosenbaum, S., et al. (2018). Effect of aerobic exercise on hippocampal volume in humans: a systematic review and meta-analysis. Neuroimage 166, 230-238. doi: 10.1016/j. neuroimage.2017.11.007

Flockhart, M., Nilsson, L. C., Tais, S., Ekblom, B., Apró, W., and Larsen, F. J. (2021). Excessive exercise training causes mitochondrial functional impairment and decreases glucose tolerance in healthy volunteers. Cell Metab. 33, 957-970.e6. doi: 10.1016/j.cmet.2021.02.017

Flowers, E., Won, G. Y., and Fukuoka, Y. (2015). MicroRNAs associated with exercise and diet: a systematic review. Physiol. Genomics 47, 1-11. doi: 10.1152/ physiolgenomics.00095.2014

Flynn, M. G., McFarlin, B. K., Phillips, M. D., Stewart, L. K., and Timmerman, K. L. (2003). Toll-like receptor 4 and CD14 mRNA expression are lower in resistive exercise-trained elderly women. J. Appl. Physiol. 95, 1833-1842. doi: 10.1152/japplphysiol.00359.2003

Forti, L. N., Van Roie, E., Njemini, R., Coudyzer, W., Beyer, I., Delecluse, C., et al. (2017). Effects of resistance training at different loads on inflammatory markers in young adults. Eur. J. Appl. Physiol. 117, 511-519.

Foster, P. P. (2015). Role of physical and mental training in brain network configuration. Front. Aging Neurosci. 7:117. doi: 10.3389/fnagi.2015.00117

Frith, E., Sng, E., and Loprinzi, P. D. (2017). Randomized controlled trial evaluating the temporal effects of high-intensity exercise on learning, short-term and long-term memory, and prospective memory. Eur. J. Neurosci. 46, 2557-2564. doi: $10.1111 /$ ejn.13719

Funcke, J.-B., and Scherer, P. E. (2019). Beyond adiponectin and leptin: adipose tissue-derived mediators of inter-organ communication. J. Lipid Res. 60, 1648 1684. doi: 10.1194/jlr.R094060

Gobbo, O. L., and O'Mara, S. M. (2005). Exercise, but not environmental enrichment, improves learning after kainic acid-induced hippocampal neurodegeneration in association with an increase in brain-derived neurotrophic factor. Behav. Brain Res. 159, 21-26. doi: 10.1016/j.bbr.2004. 09.021

Gomes, C. P., Kim, T.-K., Wang, K., and He, Y. (2015). The implications on clinical diagnostics of using microRNA-based biomarkers in exercise. Expert Rev. Mol. Diagn. 15, 761-772. doi: 10.1586/14737159.2015.1039517

Granata, C., Caruana, N. J., Botella, J., Jamnick, N. A., Huynh, K., Kuang, J., et al. (2021). Multi-omics reveal intricate network of mitochondrial adaptations to training in human skeletal muscle. bioRxiv [preprint] doi: 10.1101/2021.02.19. 431993

Grazioli, E., Dimauro, I., Mercatelli, N., Wang, G., Pitsiladis, Y., Di Luigi, L., et al. (2017). Physical activity in the prevention of human diseases: role of epigenetic modifications. BMC Genomics 18(Suppl. 8):802. doi: 10.1186/ s12864-017-4193-5

Griffin, E. W., Bechara, R. G., Birch, A. M., and Kelly, A. M. (2009). Exercise enhances hippocampal-dependent learning in the rat: evidence for a BDNFrelated mechanism. Hippocampus 19, 973-980. doi: 10.1002/hipo.20631

Grøntved, A., and Hu, F. B. (2011). Television viewing and risk of type 2 diabetes, cardiovascular disease, and all-cause mortality: a meta-analysis. JAMA 305, 2448-2455. doi: 10.1001/jama.2011.812

Guiney, H., and Machado, L. (2013). Benefits of regular aerobic exercise for executive functioning in healthy populations. Psychon. Bull. Rev. 20, 73-86. doi: $10.3758 /$ s13423-012-0345-4
Haeger, A., Costa, A. S., Schulz, J. B., and Reetz, K. (2019). Cerebral changes improved by physical activity during cognitive decline: a systematic review on MRI studies. NeuroImage 23:101933.

Hall, P. A., and Fong, G. T. (2015). Temporal self-regulation theory: a neurobiologically informed model for physical activity behavior. Front. Hum. Neurosci. 9:117. doi: 10.3389/fnhum.2015.00117

Hansen, K. F., Karelina, K., Sakamoto, K., Wayman, G. A., Impey, S., and Obrietan, K. (2013). miRNA-132: a dynamic regulator of cognitive capacity. Brain Struct. Funct. 218, 817-831. doi: 10.1007/s00429-012-0431-4

Hernandez-Rapp, J., Rainone, S., Goupil, C., Dorval, V., Smith, P. Y., SaintPierre, M., et al. (2016). microRNA-132/212 deficiency enhances A $\beta$ production and senile plaque deposition in Alzheimer's disease triple transgenic mice. Sci. Rep. 6:30953.

Hirase, H., and Shinohara, Y. (2014). Transformation of cortical and hippocampal neural circuit by environmental enrichment. Neuroscience 280, 282-298. doi: 10.1016/j.neuroscience.2014.09.031

Holloway, G. P. (2017). Nutrition and training influences on the regulation of mitochondrial adenosine diphosphate sensitivity and bioenergetics. Sports Med. 47, 13-21. doi: 10.1007/s40279-017-0693-3

Hood, D. A., Memme, J. M., Oliveira, A. N., and Triolo, M. (2019). Maintenance of skeletal muscle mitochondria in health, exercise, and aging. Annu. Rev. Physiol. 81, 19-41. doi: 10.1146/annurev-physiol-020518-114310

Hötting, K., Schickert, N., Kaiser, J., Röder, B., and Schmidt-Kassow, M. (2016). The effects of acute physical exercise on memory, peripheral BDNF, and cortisol in young adults. Neural Plast. 2016:6860573. doi: 10.1155/2016/6860573

Hu, T., Zhou, F. J., Chang, Y. F., Li, Y. S., Liu, G. C., Hong, Y., et al. (2015). miR21 is associated with the cognitive improvement following voluntary running wheel exercise in TBI mice. J. Mol. Neurosci. 57, 114-122. doi: 10.1007/s12031-0150584-8

Huang, J., Wang, X., Zhu, Y., Li, Z., Zhu, Y.-T., Wu, J.-C., et al. (2019). Exercise activates lysosomal function in the brain through AMPK-SIRT1-TFEB pathway. CNS Neurosci. Ther. 25, 796-807. doi: 10.1111/cns.13114

Huang, L., Yan, S., Luo, L., and Yang, L. (2019). Irisin regulates the expression of BDNF and glycometabolism in diabetic rats. Mol. Med. Rep. 19, 1074-1082. doi: $10.3892 / \mathrm{mmr} .2018 .9743$

Huertas, J. R., Casuso, R. A., Agustín, P. H., and Cogliati, S. (2019). Stay fit, stay young: mitochondria in movement: the role of exercise in the new mitochondrial paradigm. Oxid. Med. Cell. Longev. 2019:7058350.

Huh, J. Y., Mougios, V., Kabasakalis, A., Fatouros, I., Siopi, A., Douroudos, I. I., et al. (2014). Exercise-induced irisin secretion is independent of age or fitness level and increased irisin may directly modulate muscle metabolism through AMPK activation. J. Clin. Endocrinol. Metab. 99, E2154-E2161.

Ide, K., and Secher, N. H. (2000). Cerebral blood flow and metabolism during exercise. Prog. Neurobiol. 61, 397-414. doi: 10.1016/s0301-0082(99)00057-x

Ingerslev, B., Hansen, J. S., Hoffmann, C., Clemmesen, J. O., Secher, N. H., Scheler, M., et al. (2017). Angiopoietin-like protein 4 is an exercise-induced hepatokine in humans, regulated by glucagon and cAMP. Mol. Metab. 6, 1286-1295. doi: 10.1016/j.molmet.2017.06.018

Isaacs, K. R., Anderson, B. J., Alcantara, A. A., Black, J. E., and Greenough, W. T. (1992). Exercise and the brain: angiogenesis in the adult rat cerebellum after vigorous physical activity and motor skill learning. J. Cereb. Blood Flow Metab. 12, 110-119. doi: 10.1038/jcbfm.1992.14

Isaacs, L. (1991). Effects of exercise intensity on an accompanying timing task. J. Hum. Mov. Stud. 20, 123-131.

Janelsins, M. C., Mastrangelo, M. A., Park, K. M., Sudol, K. L., Narrow, W. C., Oddo, S., et al. (2008). Chronic neuron-specific tumor necrosis factor-alpha expression enhances the local inflammatory environment ultimately leading to neuronal death in 3xTg-AD mice. Am. J. Pathol. 173, 1768-1782.

Jessen, N. A., Munk, A. S., Lundgaard, I., and Nedergaard, M. (2015). The glymphatic system: a Beginner's guide. Neurochem. Res. 40, 2583-2599. doi: 10.1007/s11064-015-1581-6

Ji, Y., Pang, P. T., Feng, L., and Lu, B. (2005). Cyclic AMP controls BDNF-induced TrkB phosphorylation and dendritic spine formation in mature hippocampal neurons. Nat. Neurosci. 8, 164-172. doi: 10.1038/nn1381

Jia, R.-X., Liang, J.-H., Xu, Y., and Wang, Y.-Q. (2019). Effects of physical activity and exercise on the cognitive function of patients with Alzheimer disease: a meta-analysis. BMC Geriatr. 19:181. doi: 10.1186/s12877-0191175-2 
Jørgensen, L., Perko, G., and Secher, N. (1992). Regional cerebral artery mean velocity and blood flow during dynamic exercise in humans: 888 . Med. Sci. Sports Exerc. 24:S148.

Jørgensen, S. B., Treebak, J. T., Viollet, B., Schjerling, P., Vaulont, S., Wojtaszewski, J. F., et al. (2007). Role of AMPK $\alpha 2$ in basal, training-, and AICAR-induced GLUT4, hexokinase II, and mitochondrial protein expression in mouse muscle. Am. J. Physiol. Endocrinol. Metab. 292, E331-E339.

Kashihara, K., Maruyama, T., Murota, M., and Nakahara, Y. (2009). Positive effects of acute and moderate physical exercise on cognitive function. J. Physiol. Anthropol. 28, 155-164. doi: 10.2114/jpa2.28.155

Kim, D.-M., and Leem, Y.-H. (2016). Chronic stress-induced memory deficits are reversed by regular exercise via AMPK-mediated BDNF induction. Neuroscience 324, 271-285. doi: 10.1016/j.neuroscience.2016.03.019

Kim, M. W., Abid, N. B., Jo, M. H., Jo, M. G., Yoon, G. H., and Kim, M. O. (2017). Suppression of adiponectin receptor 1 promotes memory dysfunction and Alzheimer's disease-like pathologies. Sci. Rep. 7:12435. doi: 10.1038/s41598017-12632-9

Kim, S., and Kaang, B. K. (2017). Epigenetic regulation and chromatin remodeling in learning and memory. Exp. Mol. Med. 49:e281. doi: 10.1038/emm.2016.140

Kim, S., Choi, J. Y., Moon, S., Park, D. H., Kwak, H. B., and Kang, J. H. (2019). Roles of myokines in exercise-induced improvement of neuropsychiatric function. Pflugers Arch. 471, 491-505. doi: 10.1007/s00424-019-02253-8

Kjær, M. (1998). Adrenal medulla and exercise training. Eur. J. Appl. Physiol. Occup. Physiol. 77, 195-199. doi: 10.1007/s004210050321

Kong, S. H., Park, Y. J., Lee, J.-Y., Cho, N. H., and Moon, M. K. (2018). Insulin resistance is associated with cognitive decline among older Koreans with normal baseline cognitive function: a prospective community-based cohort study. Sci. Rep. 8:650. doi: 10.1038/s41598-017-18998-0

Koppel, I., and Timmusk, T. (2013). Differential regulation of Bdnf expression in cortical neurons by class-selective histone deacetylase inhibitors. Neuropharmacology 75, 106-115. doi: 10.1016/j.neuropharm.2013.07.015

Kou, X., Li, J., Liu, X., Chang, J., Zhao, Q., Jia, S., et al. (2017). Swimming attenuates d-galactose-induced brain aging via suppressing miR-34a-mediated autophagy impairment and abnormal mitochondrial dynamics. J. Appl. Physiol. 122, 1462-1469. doi: 10.1152/japplphysiol.00018.2017

Kouhestani, S., Zare, S., and Babaei, P. (2018). Flavonoids fraction of Mespilus germanica alleviates insulin resistance in metabolic syndrome model of ovariectomized rats via reduction in tumor necrosis factor- $\alpha$. J. Menopausal Med. 24, 169-175. doi: 10.6118/jmm.2018.24.3.169

Kraemer, W. J., Volek, J. S., Clark, K. L., Gordon, S. E., Puhl, S. M., Koziris, L. P., et al. (1999). Influence of exercise training on physiological and performance changes with weight loss in men. Med. Sci. Sports Exerc. 31, 1320-1329. doi: 10.1097/00005768-199909000-00014

Kramer, A. F., and Willis, S. L. (2002). Enhancing the cognitive vitality of older adults. Curr. Dir. Psychol. Sci. 11, 173-177. doi: 10.1111/1467-8721.00194

Labban, J. D., and Etnier, J. L. (2011). Effects of acute exercise on longterm memory. Res. Q. Exerc. Sport 82, 712-721. doi: 10.1080/02701367.2011. 10599808

Lambourne, K., and Tomporowski, P. (2010). The effect of exercise-induced arousal on cognitive task performance: a meta-regression analysis. Brain Res. 1341, 12-24. doi: 10.1016/j.brainres.2010.03.091

Larson, E. B., Wang, L., Bowen, J. D., McCormick, W. C., Teri, L., Crane, P., et al. (2006). Exercise is associated with reduced risk for incident dementia among persons 65 years of age and older. Ann. Intern. Med. 144, 73-81. doi: 10.7326/0003-4819-144-2-200601170-00004

Lee, I.-M., Sesso, H. D., Ridker, P. M., Mouton, C. P., Stefanick, M. L., and Manson, J. E. (2012). Physical activity and inflammation in a multiethnic cohort of women. Med. Sci. Sports Exerc. 44, 1088-1096. doi: 10.1249/mss. 0b013e318242b11a

Lewis, K., Livsey, L., Naughton, R. J., and Burton, K. (2020). Exercise and dementia: what should we be recommending? Qual. Ageing Older Adults 21, 109-127. doi: 10.1108/qaoa-10-2019-0053

Lezak, M. D., Howieson, D. B., Loring, D. W., and Fischer, J. S. (2004). Neuropsychological Assessment. New York, NY: Oxford University Press.

Li, B., Liang, F., Ding, X., Yan, Q., Zhao, Y., Zhang, X., et al. (2019). Interval and continuous exercise overcome memory deficits related to $\beta$-Amyloid accumulation through modulating mitochondrial dynamics. Behav. Brain Res. 376:112171. doi: 10.1016/j.bbr.2019.112171
Lin, J.-Y., Kuo, W.-W., Baskaran, R., Kuo, C.-H., Chen, Y.-A., Chen, W. S.-T., et al. (2020). Swimming exercise stimulates IGF1/ PI3K/Akt and AMPK/SIRT1/PGC1 $\alpha$ survival signaling to suppress apoptosis and inflammation in aging hippocampus. Aging 12, 6852-6864. doi: 10.18632/aging. 103046

Lin, Y.-S., Lin, F.-Y., and Hsiao, Y.-H. (2019). Myostatin is associated with cognitive decline in an animal model of Alzheimer's disease. Mol. Neurobiol. 56, 1984-1991. doi: 10.1007/s12035-018-1201-y

Lindberg, S., Jensen, J. S., Bjerre, M., Frystyk, J., Flyvbjerg, A., Jeppesen, J., et al. (2017). Low adiponectin levels at baseline and decreasing adiponectin levels over 10 years of follow-up predict risk of the metabolic syndrome. Diabetes Metab. 43, 134-139. doi: 10.1016/j.diabet.2016.07.027

Liu, I.-T., Lee, W.-J., Lin, S.-Y., Chang, S.-T., Kao, C.-L., and Cheng, Y.-Y. (2020). Therapeutic effects of exercise training on elderly patients with dementia: a randomized controlled trial. Arch. Phys. Med. Rehabil. 101, 762-769.

Loprinzi, P. D. (2018). Intensity-specific effects of acute exercise on human memory function: considerations for the timing of exercise and the type of memory. Health Promot. Perspect. 8:255. doi: 10.15171/hpp.2018.36

Loprinzi, P. D., Blough, J., Crawford, L., Ryu, S., Zou, L., and Li, H. (2019a). The temporal effects of acute exercise on episodic memory function: systematic review with meta-analysis. Brain Sci. 9:87.

Loprinzi, P. D., Day, S., and Deming, R. (2019b). Acute exercise intensity and memory function: evaluation of the transient hypofrontality hypothesis. Medicina (Kaunas) 55:445. doi: 10.3390/medicina55080445

Lourenco, M. V., Frozza, R. L., de Freitas, G. B., Zhang, H., Kincheski, G. C., Ribeiro, F. C., et al. (2019). Exercise-linked FNDC5/irisin rescues synaptic plasticity and memory defects in Alzheimer's models. Nat. Med. 25, 165-175. doi: 10.1038/s41591-018-0275-4

Lu, H. C., and Mackie, K. (2016). An introduction to the endogenous cannabinoid system. Biol. Psychiatry 79, 516-525. doi: 10.1016/j.biopsych.2015.07.028

Lynch, G., Rex, C. S., Chen, L. Y., and Gall, C. M. (2008). The substrates of memory: defects, treatments, and enhancement. Eur. J. Pharmacol. 585, 2-13. doi: 10.1016/j.ejphar.2007.11.082

Ma, C.-L., Ma, X.-T., Wang, J.-J., Liu, H., Chen, Y.-F., and Yang, Y. (2017). Physical exercise induces hippocampal neurogenesis and prevents cognitive decline. Behav. Brain Res. 317, 332-339. doi: 10.1016/j.bbr.2016.09.067

Maejima, H., Kanemura, N., Kokubun, T., Murata, K., and Takayanagi, K. (2018). Exercise enhances cognitive function and neurotrophin expression in the hippocampus accompanied by changes in epigenetic programming in senescence-accelerated mice. Neurosci. Lett. 665, 67-73. doi: 10.1016/j.neulet. 2017.11.023

Maejima, H., Kitahara, M., Takamatsu, Y., Mani, H., and Inoue, T. (2021). Effects of exercise and pharmacological inhibition of histone deacetylases (HDACs) on epigenetic regulations and gene expressions crucial for neuronal plasticity in the motor cortex. Brain Res. 1751:147191. doi: 10.1016/j.brainres.2020. 147191

Magila, M. C., and Xavier, G. F. (2012). Modelos de memória de longa duração em humanos. Psicol. Teoria Pesquisa 15, 037-044.

Maison, P., Walker, D. J., Walsh, F. S., Williams, G., and Doherty, P. (2009). BDNF regulates neuronal sensitivity to endocannabinoids. Neurosci. Lett. 467, 90-94. doi: 10.1016/j.neulet.2009.10.011

Mandolesi, L., Gelfo, F., Serra, L., Montuori, S., Polverino, A., Curcio, G., et al. (2017). Environmental factors promoting neural plasticity: insights from animal and human studies. Neural Plast. 2017:7219461. doi: 10.1155/2017/ 7219461

Marin Bosch, B., Bringard, A., Logrieco, M. G., Lauer, E., Imobersteg, N., Thomas, A., et al. (2021). A single session of moderate intensity exercise influences memory, endocannabinoids and brain derived neurotrophic factor levels in men. Sci. Rep. 11:14371. doi: 10.1038/s41598-021-93813-5

Marinus, N., Hansen, D., Feys, P., Meesen, R., Timmermans, A., and Spildooren, J. (2019). The impact of different types of exercise training on peripheral blood brain-derived neurotrophic factor concentrations in older adults: a meta-analysis. Sports Med. 49, 1529-1546. doi: 10.1007/s40279-019-01 $148-\mathrm{z}$

Martinez-Huenchullan, S. F., Maharjan, B. R., Williams, P. F., Tam, C. S., McLennan, S. V., and Twigg, S. M. (2018). Skeletal muscle adiponectin induction depends on diet, muscle type/activity, and exercise modality in C57BL/6 mice. Physiol. Rep. 6:e13848. doi: 10.14814/phy2.13848 
Masley, S., Roetzheim, R., and Gualtieri, T. (2009). Aerobic exercise enhances cognitive flexibility. J. Clin. Psychol. Med. Settings 16, 186-193.

McAuley, E., Szabo, A., Gothe, N., and Olson, E. A. (2011). Self-efficacy: implications for physical activity, function, and functional limitations in older adults. Am. J. Lifestyle Med. 5, 361-369. doi: 10.1177/15598276103 92704

McGaugh, J. L., Cahill, L., and Roozendaal, B. (1996). Involvement of the amygdala in memory storage: interaction with other brain systems. Proc. Natl. Acad. Sci. U.S.A. 93, 13508-13514.

McMorris, T. (2016). Developing the catecholamines hypothesis for the acute exercise-cognition interaction in humans: lessons from animal studies. Physiol. Behav. 165, 291-299. doi: 10.1016/j.physbeh.2016.08.011

McMorris, T., and Keen, P. (1994). Effect of exercise on simple reaction times of recreational athletes. Percept. Motor Skills 78, 123-130. doi: 10.2466/pms.1994. 78.1.123

Mello-Carpes, P. B., and Izquierdo, I. (2013). The nucleus of the solitary Tract $\rightarrow$ Nucleus Paragigantocellularis $\rightarrow$ Locus coeruleus $\rightarrow$ CAl region of dorsal hippocampus pathway is important for consolidation of object recognition memory. Neurobiol. Learn. Mem. 100, 56-63. doi: 10.1016/j.nlm. 2012.12.002

Meyer, J. D., Crombie, K. M., Cook, D. B., Hillard, C. J., and Koltyn, K. F. (2019). Serum endocannabinoid and mood changes after exercise in major depressive disorder. Med. Sci. Sports Exerc. 51, 1909-1917. doi: 10.1249/mss. 0000000000002006

Miyake, A., Friedman, N. P., Emerson, M. J., Witzki, A. H., Howerter, A., and Wager, T. D. (2000). The unity and diversity of executive functions and their contributions to complex "frontal lobe" tasks: a latent variable analysis. Cogn. Psychol. 41, 49-100. doi: 10.1006/cogp.1999.0734

Miyamoto-Mikami, E., Sato, K., Kurihara, T., Hasegawa, N., Fujie, S., Fujita, S., et al. (2015). Endurance training-induced increase in circulating irisin levels is associated with reduction of abdominal visceral fat in middle-aged and older adults. PLoS One 10:e0120354. doi: 10.1371/journal.pone.0120354

Miyashita, T., and Williams, C. (2006). Epinephrine administration increases neural impulses propagated along the vagus nerve: role of peripheral $\beta$ adrenergic receptors. Neurobiol. Learn. Mem. 85, 116-124. doi: 10.1016/j.nlm. 2005.08.013

Miyashita, T., and Williams, C. L. (2004). Peripheral arousal-related hormones modulate norepinephrine release in the hippocampus via influences on brainstem nuclei. Behav. Brain Res. 153, 87-95. doi: 10.1016/j.bbr.2003.11.005

Monteiro-Junior, R. S., de Tarso Maciel-Pinheiro, P., da Matta Mello Portugal, E., da Silva Figueiredo, L. F., Terra, R., Carneiro, L. S., et al. (2018). Effect of exercise on inflammatory profile of older persons: systematic review and meta-analyses. J. Phys. Act. Health 15, 64-71.

Moore, R. D., Romine, M. W., O'connor, P. J., and Tomporowski, P. D. (2012). The influence of exercise-induced fatigue on cognitive function. J. Sports Sci. 30, 841-850. doi: 10.1080/02640414.2012.675083

Morland, C., Andersson, K. A., Haugen, ØP., Hadzic, A., Kleppa, L., Gille, A., et al. (2017). Exercise induces cerebral VEGF and angiogenesis via the lactate receptor HCAR1. Nat. Commun. 8:15557.

Morris, J. K., Vidoni, E. D., Johnson, D. K., Van Sciver, A., Mahnken, J. D., Honea, R. A., et al. (2017). Aerobic exercise for Alzheimer's disease: a randomized controlled pilot trial. PLoS One 12:e0170547. doi: 10.1371/journal. pone. 0170547

Nakajima, S., Ohsawa, I., Ohta, S., Ohno, M., and Mikami, T. (2010). Regular voluntary exercise cures stress-induced impairment of cognitive function and cell proliferation accompanied by increases in cerebral IGF-1 and GST activity in mice. Behav. Brain Res. 211, 178-184. doi: 10.1016/j.bbr.2010.03.028

Navarro, A., Gomez, C., López-Cepero, J. M., and Boveris, A. (2004). Beneficial effects of moderate exercise on mice aging: survival, behavior, oxidative stress, and mitochondrial electron transfer. Am. J. Physiol. Regul. Integr. Comp. Physiol. 286, R505-R511. doi: 10.1152/ajpregu.00208.2003

Neergaard, J. S., Dragsbæk, K., Christiansen, C., Nielsen, H. B., Brix, S., Karsdal, M. A., et al. (2017). Metabolic syndrome, insulin resistance, and cognitive dysfunction: does your metabolic profile affect your brain? Diabetes 66, 19571963. doi: $10.2337 / \mathrm{db} 16-1444$

Nicola, R., and Okun, E. (2021). Adult hippocampal neurogenesis: one lactate to rule them all. NeuroMolecular Med. 23, 445-448. doi: 10.1007/s12017-02108658-y
Nikseresht, Z., Ahangar, N., Badrikoohi, M., and Babaei, P. (2021). Synergistic enhancing-memory effect of D-serine and RU360, a mitochondrial calcium uniporter blocker in rat model of Alzheimer's disease. Behav. Brain Res. 409:113307.

Nowrangi, M. A., Lyketsos, C., Rao, V., and Munro, C. A. (2014). Systematic review of neuroimaging correlates of executive functioning: converging evidence from different clinical populations. J. Neuropsychiatry Clin. Neurosci. 26, 114-125. doi: 10.1176/appi.neuropsych.12070176

Numakawa, T., Odaka, H., and Adachi, N. (2018). Actions of brain-derived neurotrophin factor in the neurogenesis and neuronal function, and its involvement in the pathophysiology of brain diseases. Int. J. Mol. Sci. 19:3650. doi: $10.3390 / \mathrm{ijms} 19113650$

Ohia-Nwoko, O., Montazari, S., Lau, Y.-S., and Eriksen, J. L. (2014). Long-term treadmill exercise attenuates tau pathology in P301S tau transgenic mice. Mol. Neurodegen. 9, 1-17.

Osellame, L. D., and Duchen, M. R. (2014). Quality control gone wrong: mitochondria, lysosomal storage disorders and neurodegeneration. $\mathrm{Br} . \mathrm{J}$. Pharmacol. 171, 1958-1972. doi: 10.1111/bph.12453

Ouchi, N., Shibata, R., and Walsh, K. (2005). AMP-activated protein kinase signaling stimulates VEGF expression and angiogenesis in skeletal muscle. Circ. Res. 96, 838-846. doi: 10.1161/01.RES.0000163633.10240.3b

Pan-Vazquez, A., Rye, N., Ameri, M., McSparron, B., Smallwood, G., Bickerdyke, J., et al. (2015). Impact of voluntary exercise and housing conditions on hippocampal glucocorticoid receptor, miR-124 and anxiety. Mol. Brain 8:40. doi: 10.1186/s13041-015-0128-8

Parastesh, M., Saremi, A., Ahmadi, A., and Kaviani, M. (2019). The effect of aerobic training on serum levels of adiponectin, hypothalamic-pituitary-gonadal axis and sperm quality in diabetic rats. Urol. J. 16, 592-597. doi: 10.22037/uj.v0i0. 4728

Pedersen, B. K. (2013). Muscle as a secretory organ. Compr. Physiol. 3, 1337-1362.

Pedersen, B. K., and Febbraio, M. A. (2012). Muscles, exercise and obesity: skeletal muscle as a secretory organ. Nat. Rev. Endocrinol. 8, 457-465. doi: 10.1038/ nrendo.2012.49

Pereira, A. C., Huddleston, D. E., Brickman, A. M., Sosunov, A. A., Hen, R., McKhann, G. M., et al. (2007). An in vivo correlate of exercise-induced neurogenesis in the adult dentate gyrus. Proc. Natl. Acad. Sci. U.S.A. 104, 5638-5643. doi: 10.1073/pnas.0611721104

Perry, V. H., Cunningham, C., and Holmes, C. (2007). Systemic infections and inflammation affect chronic neurodegeneration. Nat. Rev. Immunol. 7, 161-167. doi: 10.1038/nri2015

Pesta, D., and Roden, M. (2017). The Janus head of oxidative stress in metabolic diseases and during physical exercise. Curr. Diabetes Rep. 17:41. doi: 10.1007/ s11892-017-0867-2

Plassman, B. L., Langa, K. M., Fisher, G. G., Heeringa, S. G., Weir, D. R., Ofstedal, M. B., et al. (2007). Prevalence of dementia in the United States: the aging, demographics, and memory study. Neuroepidemiology 29, 125-132. doi: 10. $1159 / 000109998$

Pousti, F., Ahmadi, R., Mirahmadi, F., Hosseinmardi, N., and Rohampour, K. (2018). Adiponectin modulates synaptic plasticity in hippocampal dentate gyrus. Neurosci. Lett. 662, 227-232. doi: 10.1016/j.neulet.2017.10.042

Pyke, W., Ifram, F., Coventry, L., Sung, Y., Champion, I., and Javadi, A.-H. (2020). The effects of different protocols of physical exercise and rest on long-term memory. Neurobiol. Learn. Mem. 167:107128. doi: 10.1016/j.nlm.2019.107128

Quan, H., Koltai, E., Suzuki, K., Aguiar, A. S. Jr., Pinho, R., Boldogh, I., et al. (2020). Exercise, redox system and neurodegenerative diseases. Biochim. Biophys. Acta BBA.Mol. Basis Dis. 1866:165778. doi: 10.1016/j.bbadis.2020.165778

Radom-Aizik, S., Zaldivar, F. Jr., Leu, S. Y., Adams, G. R., Oliver, S., and Cooper, D. M. (2012). Effects of exercise on microRNA expression in young males peripheral blood mononuclear cells. Clin. Transl. Sci. 5, 32-38. doi: 10.1111/ j.1752-8062.2011.00384.x

Rathore, A., and Lom, B. (2017). The effects of chronic and acute physical activity on working memory performance in healthy participants: a systematic review with meta-analysis of randomized controlled trials. Syst. Rev. 6, 1-16. doi: 10.1186/s13643-017-0514-7

Razay, G., Vreugdenhil, A., and Wilcock, G. (2007). The metabolic syndrome and Alzheimer disease. Arch. Neurol. 64, 93-96.

Rizzo, M. R., Fasano, R., and Paolisso, G. (2020). Adiponectin and cognitive decline. Int. J. Mol. Sci. 21, 2010. 
Rolland, Y., Pillard, F., Klapouszczak, A., Reynish, E., Thomas, D., Andrieu, S., et al. (2007). Exercise program for nursing home residents with Alzheimer's disease: a 1-year randomized, controlled trial. J. Am. Geriatr. Soc. 55, 158-165. doi: 10.1111/j.1532-5415.2007.01035.x

Ruscheweyh, R., Willemer, C., Krüger, K., Duning, T., Warnecke, T., Sommer, J., et al. (2011). Physical activity and memory functions: an interventional study. Neurobiol. Aging 32, 1304-1319. doi: 10.1016/j.neurobiolaging.2009. 08.001

Samarghandian, S., Azimi-Nezhad, M., and Farkhondeh, T. (2016). Crocin attenuate Tumor Necrosis Factor-alpha (TNF- $\alpha$ ) and interleukin-6 (IL-6) in streptozotocin-induced diabetic rat aorta. Cytokine 88, 20-28. doi: 10.1016/j. cyto.2016.08.002

Samuel, R. D., Zavdy, O., Levav, M., Reuveny, R., Katz, U., and Dubnov-Raz, G. (2017). The effects of maximal intensity exercise on cognitive performance in children. J. Hum. Kinet. 57:85. doi: 10.1515/hukin-2017-0050

Santilli, F., DArdes, D., Teresa Guagnano, M., and Davi, G. (2017). Metabolic syndrome: sex-related cardiovascular risk and therapeutic approach. Curr. Med. Chem. 24, 2602-2627. doi: 10.2174/09298673246661707101 21145

Santos, D. (1994). Influência do Exercício Físico Intenso Sobre a Memória Recente (Dissertação de Mestrado). Porto Alegre: UFRGS.

Scandella, V., and Knobloch, M. (2019). Sensing the environment: extracellular lactate levels control adult neurogenesis. Cell Stem Cell 25, 729-731. doi: 10. 1016/j.stem.2019.11.008

Scott, H. L., Tamagnini, F., Narduzzo, K. E., Howarth, J. L., Lee, Y. B., Wong, L. F., et al. (2012). MicroRNA-132 regulates recognition memory and synaptic plasticity in the perirhinal cortex. Eur. J. Neurosci. 36, 2941-2948. doi: 10.1111/ j.1460-9568.2012.08220.x

Scott, W. A. (1962). Cognitive complexity and cognitive flexibility. Sociometry 25 , 405-414. doi: 10.2307/2785779

Segabinazi, E., Gasperini, N. F., Faustino, A. M., Centeno, R., Dos Santos, A., Almeida, W. D., et al. (2020). Comparative overview of the effects of aerobic and resistance exercise on anxiety-like behavior, cognitive flexibility, and hippocampal synaptic plasticity parameters in healthy rats. Braz. J. Med. Biol. Res. 53:e9816.

Seifi-Skishahr, F., Damirchi, A., Farjaminezhad, M., and Babaei, P. (2016). Physical training status determines oxidative stress and redox changes in response to an acute aerobic exercise. Biochem. Res. Int. 2016:3757623. doi: 10.1155/2016/ 3757623

Seldin, M. M., Peterson, J. M., Byerly, M. S., Wei, Z., and Wong, G. W. (2012). Myonectin (CTRP15), a novel myokine that links skeletal muscle to systemic lipid homeostasis. J. Biol. Chem. 287, 11968-11980. doi: 10.1074/jbc.M111. 336834

Selvam, R., Yeh, M. L., and Levine, E. S. (2018). Endogenous cannabinoids mediate the effect of BDNF at CA1 inhibitory synapses in the hippocampus. Synapse (New York, N.Y.) 73:e22075. doi: 10.1002/syn.22075

Sheet, E. F. F. (2005). Learning Disabilities Executive Function Fact Sheet. Learning Disabilities:(NCLD). www.nsadhd.org.uploads. Washington, DC: National Center for Learning Disabilities.

Short, K. R., Bigelow, M. L., Kahl, J., Singh, R., Coenen-Schimke, J., Raghavakaimal, S., et al. (2005). Decline in skeletal muscle mitochondrial function with aging in humans. Proc. Natl. Acad. Sci. U.S.A. 102, 5618-5623. doi: 10.1073/pnas. 0501559102

Sibley, B. A., Etnier, J., and Masurier, G. L. (2006). Effects of an acute bout of exercise on cognitive aspects of Stroop performance. J. Sport Exerc. Psychol. 28, 285-299.

Silvestri, C., and Di Marzo, V. (2013). The endocannabinoid system in energy homeostasis and the etiopathology of metabolic disorders. Cell Metab. 17, 475-490. doi: 10.1016/j.cmet.2013.03.001

Sjøberg, K. A., Frøsig, C., Kjøbsted, R., Sylow, L., Kleinert, M., Betik, A. C., et al. (2017). Exercise increases human skeletal muscle insulin sensitivity via coordinated increases in microvascular perfusion and molecular signaling. Diabetes 66, 1501-1510. doi: 10.2337/db16-1327

Sleiman, S. F., Henry, J., Al-Haddad, R., El Hayek, L., Abou Haidar, E., Stringer, T., et al. (2016). Exercise promotes the expression of brain derived neurotrophic factor (BDNF) through the action of the ketone body $\beta$-hydroxybutyrate. Elife 5:e15092. doi: 10.7554/eLife.15092
Smith, P., Blumenthal, J., Hoffman, B., Cooper, H., Strauman, T. A., WelshBohmer, K., et al. (2010). Aerobic exercise and neurocognitive performance: a metaanalytic review of randomized controlled trials. Psychosom. Med. 72, 239-252. doi: 10.1097/psy.0b013e3181d14633

Smith, P. Y., Hernandez-Rapp, J., Jolivette, F., Lecours, C., Bisht, K., Goupil, C., et al. (2015). miR-132/212 deficiency impairs tau metabolism and promotes pathological aggregation in vivo. Hum. Mol. Genet. 24, 6721-6735. doi: 10.1093/ hmg/ddv377

Sng, E., Frith, E., and Loprinzi, P. D. (2018). Temporal effects of acute walking exercise on learning and memory function. Am. J. Health Promot. 32, 15181525. doi: 10.1177/0890117117749476

Steiner, B., Kronenberg, G., Jessberger, S., Brandt, M. D., Reuter, K., and Kempermann, G. (2004). Differential regulation of gliogenesis in the context of adult hippocampal neurogenesis in mice. Glia 46, 41-52. doi: 10.1002/glia. 10337

Steiner, J. L., Murphy, E. A., McClellan, J. L., Carmichael, M. D., and Davis, J. M. (2011). Exercise training increases mitochondrial biogenesis in the brain. J. Appl. Physiol. 111, 1066-1071. doi: 10.1152/japplphysiol.00343.2011

Stone, N. L., Millar, S. A., Herrod, P. J. J., Barrett, D. A., Ortori, C. A., Mellon, V. A., et al. (2018). An analysis of endocannabinoid concentrations and mood following singing and exercise in healthy volunteers. Front. Behav. Neurosci. 12:269. doi: 10.3389/fnbeh.2018.00269

Sun, N., Youle, R. J., and Finkel, T. (2016). The mitochondrial basis of aging. Mol. Cell 61, 654-666. doi: 10.1016/j.molcel.2016.01.028

Sutoo, D. E., and Akiyama, K. (2003). Regulation of brain function by exercise. Neurobiol. Dis. 13, 1-14.

Szuhany, K. L., Bugatti, M., and Otto, M. W. (2015). A meta-analytic review of the effects of exercise on brain-derived neurotrophic factor. J. Psychiatr. Res. 60, 56-64. doi: 10.1016/j.jpsychires.2014.10.003

Tanaka, J., Horiike, Y., Matsuzaki, M., Miyazaki, T., Ellis-Davies, G. C., and Kasai, H. (2008). Protein synthesis and neurotrophin-dependent structural plasticity of single dendritic spines. Science 319, 1683-1687. doi: 10.1126/science.1152864

Tapia-Arancibia, L., Aliaga, E., Silhol, M., and Arancibia, S. (2008). New insights into brain BDNF function in normal aging and Alzheimer disease. Brain Res. Rev. 59, 201-220. doi: 10.1016/j.brainresrev.2008.07.007

Teixeira, A. L., Diniz, B. S., Campos, A. C., Miranda, A. S., Rocha, N. P., Talib, L. L., et al. (2013). Decreased levels of circulating adiponectin in mild cognitive impairment and Alzheimer's disease. NeuroMolecular Med. 15, 115-121. doi: 10.1007/s12017-012-8201-2

Ten Brinke, L. F., Bolandzadeh, N., Nagamatsu, L. S., Hsu, C. L., Davis, J. C., MiranKhan, K., et al. (2015). Aerobic exercise increases hippocampal volume in older women with probable mild cognitive impairment: a 6-month randomised controlled trial. Br. J. Sports Med. 49, 248-254. doi: 10.1136/bjsports-2013093184

Toloza, F. J., Mantilla-Rivas, J. O., Pérez-Matos, M. C., Ricardo-Silgado, M. L., Morales-Alvarez, M. C., Pinzón-Cortés, J. A., et al. (2018). Plasma levels of myonectin but not myostatin or fibroblast-derived growth factor 21 are associated with insulin resistance in adult humans without diabetes mellitus. Front. Endocrinol. 9:5. doi: 10.3389/fendo.2018.00005

Tore, F., Tonchev, A., Fiore, M., Tunçel, N., Atanassova, P., Aloe, L., et al. (2007). From adipose tissue protein secretion to adipopharmacology of disease. Immunol. Endocr. Metab. Agents Med.Chem. Formerly Curr. Med. Chem. Immunol. Endocr. Metab. Agents 7, 149-155. doi: 10.2174/187152207780363712

Trejo, J. L., Carro, E., and Torres-Aleman, I. (2001). Circulating insulin-like growth factor I mediates exercise-induced increases in the number of new neurons in the adult hippocampus. J. Neurosci. 21, 1628-1634. doi: 10.1523/jneurosci.2105-01628.2001

Tsai, C.-L., Ukropec, J., Ukropcová, B., and Pai, M.-C. (2018). An acute bout of aerobic or strength exercise specifically modifies circulating exerkine levels and neurocognitive functions in elderly individuals with mild cognitive impairment. NeuroImage 17, 272-284. doi: 10.1016/j.nicl.2017.10.028

Tsai, S.-F., Ku, N.-W., Wang, T.-F., Yang, Y.-H., Shih, Y.-H., Wu, S.-Y., et al. (2018). Long-term moderate exercise rescues age-related decline in hippocampal neuronal complexity and memory. Gerontology 64, 551-561. doi: 10.1159/ 000488589

Tsai, W.-L., Chen, H.-Y., Huang, Y.-Z., Chen, Y.-H., Kuo, C.-W., Chen, K.-Y., et al. (2019). Long-Term voluntary physical exercise exerts neuroprotective effects 
and motor disturbance alleviation in a rat model of Parkinson's disease. Behav. Neurol. 2019:4829572. doi: 10.1155/2019/4829572

Utiger, R. D. (2011). Insulin-Like Growth Factor [Online]. Encyclopedia Britannica. Available online at: https://www.britannica.com/science/insulin-like-growthfactor

Vardy, E. R., Rice, P. J., Bowie, P. C., Holmes, J. D., Grant, P. J., and Hooper, N. M. (2007). Increased circulating insulin-like growth factor-1 in late-onset Alzheimer's disease. J. Alzheimers Dis. 12, 285-290. doi: 10.3233/jad-200712401

Vega, R. B., Konhilas, J. P., Kelly, D. P., and Leinwand, L. A. (2017). Molecular mechanisms underlying cardiac adaptation to exercise. Cell Metab. 25, 1012 1026. doi: 10.1016/j.cmet.2017.04.025

von Holstein-Rathlou, S., Petersen, N. C., and Nedergaard, M. (2018). Voluntary running enhances glymphatic influx in awake behaving, young mice. Neurosci. Lett. 662, 253-258. doi: 10.1016/j.neulet.2017.10.035

Voss, M. W., Erickson, K. I., Prakash, R. S., Chaddock, L., Kim, J. S., Alves, H., et al. (2013). Neurobiological markers of exercise-related brain plasticity in older adults. Brain Behav. Immun. 28, 90-99. doi: 10.1016/j.bbi.2012. 10.021

Voss, M. W., Erickson, K. I., Prakash, R. S., Chaddock, L., Malkowski, E., Alves, H., et al. (2010). Functional connectivity: a source of variance in the association between cardiorespiratory fitness and cognition? Neuropsychologia 48, 13941406. doi: 10.1016/j.neuropsychologia.2010.01.005

Vreugdenhil, A., Cannell, J., Davies, A., and Razay, G. (2012). A community-based exercise programme to improve functional ability in people with Alzheimer's disease: a randomized controlled trial. Scand. J. Caring Sci. 26, 12-19. doi: 10.1111/j.1471-6712.2011.00895.x

Wang, H., and Han, J. (2020). The endocannabinoid system regulates the moderate exercise-induced enhancement of learning and memory in mice. J. Sports Med. Phys. Fitness 60, 320-328. doi: 10.23736/s0022-4707.19.10 235-6

Wang, R. Y., Phang, R. Z., Hsu, P. H., Wang, W. H., Huang, H. T., and Liu, I. Y. (2013). In vivo knockdown of hippocampal miR-132 expression impairs memory acquisition of trace fear conditioning. Hippocampus 23, 625-633. doi: 10.1002/hipo. 22123

Watson, G. S., and Craft, S. (2004). Modulation of memory by insulin and glucose: neuropsychological observations in Alzheimer's disease. Eur. J. Pharmacol. 490, 97-113.

Whitham, M., and Febbraio, M. A. (2016). The ever-expanding myokinome: discovery challenges and therapeutic implications. Nat. Rev. Drug Discov. 15, 719-729. doi: $10.1038 /$ nrd.2016.153

Wilke, J. (2020). Functional high-intensity exercise is more effective in acutely increasing working memory than aerobic walking: an exploratory randomized, controlled trial. Sci. Rep. 10:12335. doi: 10.1038/s41598-020-69139-z

Williams, C. L., Men, D., and Clayton, E. C. (2000). The effects of noradrenergic activation of the nucleus tractus solitarius on memory and in potentiating norepinephrine release in the amygdala. Behav. Neurosci. 114:1131. doi: 10. 1037//0735-7044.114.6.1131

Winter, B., Breitenstein, C., Mooren, F. C., Voelker, K., Fobker, M., Lechtermann, A., et al. (2007). High impact running improves learning. Neurobiol. Learn. Mem. 87, 597-609. doi: 10.1016/j.nlm.2006.11.003

World Health Organization (2020). Dementia [Online]. Available online at: https: //www.who.int/news-room/fact-sheets/detail/dementia (accessed February 09, 2021).
World Health Organization (2019). Risk Reduction of Cognitive Decline and Dementia WHO Guidelines. Geneva: World Health Organization.

Wrann, C. D., White, J. P., Salogiannnis, J., Laznik-Bogoslavski, D., Wu, J., Ma, D., et al. (2013). Exercise induces hippocampal BDNF through a PGC-1 $\alpha /$ FNDC5 pathway. Cell Metab. 18, 649-659. doi: 10.1016/j.cmet.2013.09.008

Wu, C. W., Chang, Y. T., Yu, L., Chen, H. I., Jen, C. J., Wu, S. Y., et al. (2008). Exercise enhances the proliferation of neural stem cells and neurite growth and survival of neuronal progenitor cells in dentate gyrus of middle-aged mice. J. Appl. Physiol. 105, 1585-1594. doi: 10.1152/japplphysiol.90775.2008

Wu, Y., Liu, Q., Guo, B., Ye, F., Ge, J., and Xue, L. (2020). BDNF activates postsynaptic TrkB receptors to induce endocannabinoid release and inhibit presynaptic calcium influx at a Calyx-Type synapse. J. Neurosci. 40, 8070-8087. doi: 10.1523/jneurosci.2838-19.2020

Xu, L., Zheng, Y. L., Yin, X., Xu, S. J., Tian, D., Zhang, C. Y., et al. (2020). Excessive treadmill training enhances brain-specific MicroRNA-34a in the mouse hippocampus. Front. Mol. Neurosci. 13:7. doi: 10.3389/fnmol.2020.00007

Xu, T., Liu, Q., Yao, J., Dai, Y., Wang, H., and Xiao, J. (2015). Circulating microRNAs in response to exercise. Scand. J. Med. Sci. Sports 25, e149-e154.

Yeh, M. L., Selvam, R., and Levine, E. S. (2017). BDNF-induced endocannabinoid release modulates neocortical glutamatergic neurotransmission. Synapse 71:e21962. doi: 10.1002/syn.21962

Yoon, K. J., Zhang, D., Kim, S.-J., Lee, M.-C., and Moon, H. Y. (2019). Exerciseinduced AMPK activation is involved in delay of skeletal muscle senescence. Biochem. Biophys. Res. Commun. 512, 604-610.

Zhang, W., Chang, L., Zhang, C., Zhang, R., Li, Z., Chai, B., et al. (2015). Irisin: a myokine with locomotor activity. Neurosci. Lett. 595, 7-11. doi: 10.1016/j. neulet.2015.03.069

Zhang, X., Xu, A., Chung, S. K., Cresser, J. H., Sweeney, G., Wong, R. L., et al. (2011). Selective inactivation of c-Jun NH2-terminal kinase in adipose tissue protects against diet-induced obesity and improves insulin sensitivity in both liver and skeletal muscle in mice. Diabetes 60, 486-495. doi: 10.2337/db10-0650

Zorova, L. D., Popkov, V. A., Plotnikov, E. Y., Silachev, D. N., Pevzner, I. B., Jankauskas, S. S., et al. (2018). Mitochondrial membrane potential. Anal. Biochem. 552, 50-59.

Zou, S., and Kumar, U. (2018). Cannabinoid receptors and the endocannabinoid system: signaling and function in the central nervous system. Int. J. Mol. Sci. 19:833. doi: 10.3390/ijms19030833

Conflict of Interest: The authors declare that the research was conducted in the absence of any commercial or financial relationships that could be construed as a potential conflict of interest.

Publisher's Note: All claims expressed in this article are solely those of the authors and do not necessarily represent those of their affiliated organizations, or those of the publisher, the editors and the reviewers. Any product that may be evaluated in this article, or claim that may be made by its manufacturer, is not guaranteed or endorsed by the publisher.

Copyright (c) 2022 Babaei and Azari. This is an open-access article distributed under the terms of the Creative Commons Attribution License (CC BY). The use, distribution or reproduction in other forums is permitted, provided the original author(s) and the copyright owner(s) are credited and that the original publication in this journal is cited, in accordance with accepted academic practice. No use, distribution or reproduction is permitted which does not comply with these terms. 